\title{
Profit-sharing Rules and the Taxation of Multinational Internet Platforms
}

\author{
Francis Bloch* Gabrielle Demange ${ }^{\dagger}$
}

January 10, 2020

\begin{abstract}
We analyze the strategy of a monopolistic Internet platform serving users from two jurisdictions with different corporate tax rates. We show that the platform exploits positive externalities across users to shift profit, and study the effects of a change in the corporate tax rate of one of the two jurisdictions. When externalities flow symmetrically among users in both jurisdictions, the platform increases quantities in the high tax jurisdiction and reduces quantities in the low tax jurisdiction. When externalities only flow from one jurisdiction to another, the platform's response depends on the direction of externalities. If externalities originate in the high tax jurisdiction, the platform increases quantities in the high tax jurisdiction ; if they originate in the low tax jurisdiction, the platform reduces quantities in the low tax jurisdiction. We contrast the baseline regime of separate accounting (SA) with a regime of Formula Apportionment (FA), where the tax bill is apportioned in proportion to the number of users in the two jurisdictions. Under FA, the platform always increases quantities in the lower-tax jurisdiction and decreases quantities in the higher-tax jurisdiction. We use a numerical simulation to show that the higher-tax jurisdiction prefers SA to FA whereas the lower-tax jurisdiction prefers FA to SA.
\end{abstract}

JEL Classification Numbers: H32, H25, L12, L14.

Keywords: Digital platforms, multinational firms, corporate income taxation, Formula Apportionment, separate accounting

\footnotetext{
${ }^{*}$ Paris School of Economics-Université Paris 1, 48 Boulevard Jourdan, 75014 Paris, France. Email francis.bloch@univ-paris1.fr.

${ }^{\dagger}$ Paris School of Economics-EHESS, 48 Boulevard Jourdan, 75014 Paris, France. Email demange@pse.ens.fr.
} 


\section{Introduction}

Internet platforms often connect agents living under different fiscal jurisdictions. Facebook and Google users receive targeted advertising from companies headquartered outside their jurisdiction of residence. Sellers and buyers on E-bay transact with agents living in different jurisdictions. Booking or Expedia users book flights and hotels all over the world. As users benefit from positive externalities due to the presence of other users on the platform, the surplus created by the platform cannot easily be ascribed to a specific fiscal jurisdiction, raising difficult issues when the jurisdictions fix different corporate income tax rates. In this paper, our objective is precisely to analyze the effect of differences in corporate tax rates on the behavior of Internet platforms operating in different jurisdictions.

The issue of taxation of the profits of Internet platforms has recently received considerable attention from policy-makers. Digital companies are known to pay very low corporate income taxes in the countries in which they operate. Recognizing this fact, the OECD has launched a specific action to address the tax challenges in the digital economy in the Base Erosion and Profit Shifting (BEPS) project. In May 2019, the 129 countries participating in the BEPS discussions have approved a programme of work based on two pillars (OECD, 2019). The first pillar contains a reform of the definition of "permanent establishment" to allow countries where Internet platforms operate to tax corporate income and new sharing rules based on revenues and users to allocate profit across countries. The second pillar provides rules for countries to "tax back" profits when they are inadequately taxed in other countries. In the meantime, while this programme is still under discussion, some countries are contemplating imposing taxes on the revenues of Internet platform unilaterally. In July 2019, the French parliament passed a law imposing a tax of $3 \%$ on the revenues based on intermediation and targeted advertising of 27 large digital platforms. ${ }^{1}$ Other countries are following suit. Austria has passed in October 2019 a law imposing a tax of $5 \%$ on online advertising. Turkey, the UK, Belgium and Spain are also planning to introduce taxes on digital services (ranging from $2 \%$ in the UK to $7.5 \%$ in Turkey) in $2020 .^{2}$

In this paper, we contribute to the study of profit-shifting and profit-sharing of digital platforms, by considering a simple model where a monopolistic platform operates in two jurisdictions. Users in one jurisdiction benefit from positive externalities generated by the users in the other jurisdiction. This general formulation covers two-sided markets, where users on the two sides of the market are located in different jurisdictions (e.g. search engines and digital social media, where advertisers are located in a small, low tax jurisdiction whereas users are located in a large, high tax jurisdiction) as well as peer-to-peer markets, where users located in the two jurisdictions can both be buyers and sellers (e.g. on-line market places and auction sites, matching and file-sharing platforms). In the baseline model (Separate Accounting), we assume that each jurisdiction taxes the profits made in that jurisdiction. We suppose that users are immobile, or, equivalently, that users' location decisions are made independently of the corporate tax rates on the platform. We also assume zero marginal cost and abstract from fixed investment costs so

\footnotetext{
${ }^{1}$ France leads the way on taxing tech more fairly, The Financial Times, July 11, 2019.

${ }^{2}$ Why digital taxes are the new trade war flashpoint, The Washington Post, December 10, 2019.
} 
that profits and revenues are identical. Transfer pricing through royalties on intangible assets is not incorporated into the analysis. Our interest bears on the impact of different tax rates on the platform's strategy in the two jurisdictions. ${ }^{3}$

Our first result shows that, even in the absence of transfer pricing, the platform can exploit externalities to shift profits from a high tax jurisdiction to a low tax jurisdiction. More precisely, we analyze the comparative statics effect of an increase in the corporate tax rate of one of the two jurisdictions on the strategy of the platform. If we start from a situation where the two platforms set equal corporate income tax rates, this comparative statics study shows how the platform distorts its optimal quantities in jurisdictions with high and low corporate tax rates.

We start by analyzing how changes in the corporate tax rate affect directly the choices of the platform in the two jurisdictions. In order to reduce its tax bill, the platform distorts its quantities to reduce profit in the jurisdiction with higher tax rate and increase it in the jurisdiction with lower tax rate. Because of positive externalities across markets, the optimal distortion involves an increase in quantities in the higher tax jurisdiction, and a decrease in quantities in the lower tax jurisdiction. These are direct of the increase in the corporate tax rate, which need to be balanced with indirect effects due to the reaction of users on one side of the market to the number of users on the other side. By increasing the number of users in the higher tax jurisdiction or decreasing the number of users in the lower tax jurisdiction, the platform generates a change in the demand in the other jurisdiction. When markets are "substitutes", an increase in the demand in one jurisdiction induces a decrease in the demand of the other. In the more plausible case where markets are "complements", an increase in the demand in one jurisdiction results in an increase in the demand of the other. In the latter case, the direct and indirect effects have opposite signs and the overall effect cannot be ascertained in general. To determine how an increase in the corporate tax rate affects the number of users in both jurisdictions, we examine two particular situations.

We first consider markets where externalities only flow from one jurisdiction to the other. This assumption captures situations where one side of the market (advertisers located in Ireland) experience positive externalities from the other side of the market (users located in France), whereas the converse is not true. Suppose, keeping in mind the example of users and advertisers, that externalities flow from the high tax jurisdiction to the low tax jurisdiction. The optimal size of the advertising market in the low tax jurisdiction is then independent of the corporate tax rate. Hence an increase in the corporate tax rate of the high tax jurisdiction has no direct effect on the number of advertisers, and the direct effect only results in an increase in the number of users in the high tax jurisdiction. In reaction, the number of advertisers served by the platform in the low tax jurisdiction decreases in the (unlikely case) of substitute markets, and increases in the (more relevant case) of complementary markets.

When externalities flow from the low tax jurisdiction to the high tax jurisdiction, the effects are reversed. An increase in the corporate tax rate of the high tax jurisdiction leads to a reduction in the number of users in the low- tax jurisdiction, and either a decrease or an increase in the number of users in the high tax jurisdiction, depending on whether markets are comple-

\footnotetext{
${ }^{3}$ The model could easily be adapted to deal with direct rather than indirect taxes, as we assume that there is no transfer pricing and no marginal cost of production.
} 
ments or substitutes. Notice that the only case which cannot occur is that we cannot observe simultaneously a decrease in the number of users in the high tax jurisdiction and an increase in the number of users in the low tax jurisdiction.

Second, we consider markets which are symmetric and balanced: the two markets have equal size, the pattern of externalities is similar, and the tax rates are initially identical. This situation corresponds to peer-to-peer platforms like E-bay or Spotify operating in two similar, large jurisdictions, such as France and Germany. We show that the direct effect always dominates the indirect effect so that an increase in the corporate tax rate leads to an increase in the number of users and a decrease in price in the high tax jurisdiction and a reduction in the number of users and an increase in price in the low tax jurisdiction. As the corporate tax rate continues to increase, the price in the high tax jurisdiction becomes negligible, giving an alternative explanation to the fact that a platform may optimally choose not to charge some of its users.

In order to quantify the interplay between externalities, market sizes and corporate tax rates, we then resort to a linear model. We compute precisely the optimal choices of the platform, and discuss the comparative statics effects of changes in the parameters on the optimal prices, quantities and the tax revenues in the two jurisdictions.

We next analyze a profit-sharing rule where profit is apportioned according to the number of users rather than the revenues. Following the traditional terminology, the new sharing rule is called Formula Apportionment while the baseline sharing rule is termed Separate Accounting . We show that the direction of the direct effect of an increase in the corporate tax rate under Formula Apportionment is the reverse of the direction under Separate Accounting. In order to lower its tax bill, the platform increases the number of users in the low tax jurisdiction and decreases the number of users in the high tax jurisdiction. Externalities across jurisdictions and the apportionment key give rise to an indirect effect: if the number of users in the low tax jurisdiction increases, demand in the high tax jurisdiction goes up, pushing up the number of users and the share of profits taxed in the high tax-jurisdiction. We characterize two situations where the direct effect dominates the indirect effect around identical tax rates: (i) when markets are symmetric and balanced and (ii) in the absence of externalities across jurisdictions. In both situations, a higher corporate tax rate results in a decrease in the number of users in the high tax jurisdiction and an increase in the number of users in the low tax jurisdiction.

Finally, we use a numerical simulation to compare profits and tax revenues of a peer-topeer platform under Separate Accounting and Formula Apportionment. We first show that the comparative statics results obtained locally around identical tax rates are robust, and that the direct effect dominates the indirect effect for the entire range of tax rate values. Distortions in the number of users are stronger under FA than under SA, resulting in lower pre-tax profit. However, the tax bill of the platform is higher under SA than under FA, so that post-tax profits are comparable in the two régimes. Tax revenues in the high tax jurisdiction are higher under SA than under FA, but tax revenues in the low tax jurisdiction are higher under FA than under SA, suggesting that the two jurisdictions will disagree in the choice of the profit-sharing régime.

The rest of the paper is organized as follows. We discuss the related literature in the next subsection. We present the model in Section 2. In Section 3, we analyze the benchmark model 
under Separate Accounting. The model with Formula Apportionment is discussed in Section 4. Section 5 presents the results of a numerical simulation comparing the two régimes. Section 6 concludes.

\section{Relation to the literature}

This paper is related to two different strands of the literature: the literature on taxation of two-sided platforms and the literature on Formula Apportionment. Optimal taxation of twosided monopolistic platforms have been studied by Kind et al. (2008, 2009, 2010, 2013) and Bourreau, Caillaud and de Nijs (2018). In Kind et al. (2008, 2009, 2010, 2013), the two sides of the market are located in the same jurisdiction and tax rates are equal on revenues generated by the two sides of the market. The studies of Kind et al. (2008, 2009, 2010, 2013) have generated two main results. First, they show that ad valorem taxes (like VAT) do not necessarily dominate unit taxes. The classical result in public finance on the domination of ad valorem taxes no longer holds for two-sided markets. Second, the price of a good may decrease with the ad valorem tax. The introduction of a tax on the value added for one side of the market can lead to a change in the entire business model of the platform. For example, the increase in VAT on the price of access for users could induce the platform to set a zero price for Internet access and switch all its revenues to the advertisers side. Bourreau, Caillaud and de Nijs (2018) supplement the model of the two-sided platform by considering data collection and letting consumers select the flow of data uploaded to the platform. They allow for different taxes levied on the two sides of the market (a tax based on data uploaded by users and an ad valorem tax paid by advertisers). Their main result shows that a small increase in the tax rate on data collection above zero results in an increase in fiscal revenues and an increase in the prices and quantities of the platform. By contrast to our paper, they do not provide a general analysis of the comparative statics effect of changes on the tax rate on one side of the market.

Kotsogiannis and Serfes (2010) study competition between two platforms located in different jurisdictions. jurisdictions choose both a tax rate and a level of public good. Consumers and businesses choose which platform to go to, taking into account the tax rate and public good provision in both jurisdictions. If the difference in public good provision in the two jurisdictions is large, each platform specializes in one segment of the population. If the difference in public good provision is small, competition between platforms is fierce, and all consumers and all businesses may choose to join a single platform. Comparative statics results show that an increase in externalities between the two sides of the market may lead to a decrease in the tax rate in both jurisdictions, an increase in the number of firms on platform $A$ and a decrease in the number of firms on platform $B$. The model of Kotsogiannis and Serfes (2010) differs from ours in several respects. First they consider perfectly mobile users on the two sides of the market, second they assume competition between two platforms located in the two jurisdictions. Finally, they consider taxation on firms and businesses whereas we analyze corporate income taxes paid by a monopolistic platform.

The literature on Formula Apportionment originates with a paper by Gordon and Wilson (1986) who show that the formula used in the United States, which puts positive weight on sales, wages and assets induces distortions in the optimal choice of inputs by the firms. Anand and 
Sansing (2000) analyze a model where two states bargain over the weights to place on different indicators and show that the weights placed on sales and inputs are typically inefficient in a decentralized equilibrium. Nielsen, Raimondos Moller and Schjelderup (2003) compare SA and FA in a model where transfer prices are used to manipulate the behavior of a subsidiary in an oligopolistic market. Kind, Midelfart and Schjelederup (2005) extend the model by considering a first stage of tax competition where two jurisdictions simultaneously select their corporate income tax rate to maximize fiscal revenues. Nielsen, Raimondos-Moller and Schjelderup (2010) analyze capital investment decisions of a multinational under the two régimes of SA and FA around symmetric tax rates. Finally, Gresik (2010) compares SA and FA when the production cost of the intermediate output is privately known by the multinational. None of the literature on Formula Apportionment has considered externalities in demand across jurisdictions as we do in this paper.

\section{The model}

We analyze the strategy of a monopolistic platform operating in two jurisdictions with possibly different corporate tax rates. The services provided by Internet platforms are very diverse, ranging from intermediation between buyers and sellers (like Amazon market place, which connects customers and sellers Booking, which connects customers and hotels and AirBnb which connects renters and homeowners) to social media (like Facebook, which allows users to be connected and connects advertisers to users), search engines (like Google, which connects advertisers to users), and collaborative and peer-to-peer platforms (like E-bay, Meetic, Spotify and Airbnb, which connect users trading goods, looking for romantic relationships or sharing music) The simple model we introduce in the next section captures some of these situations (but not all).

We distinguish between platforms connecting users of the same type and connecting two different types of users. Peer-to-peer or collaborative platforms connect users of the same type living in different jurisdictions. Other platforms, like search engines or intermediation platforms, connect two different types of users (advertisers and users, buyers and sellers..) When the platform is two-sided, we assume that users on the same side of the market all reside in the same jurisdiction. This situation arises when buyers and sellers are located in different jurisdictions (e.g. German customers searching for hotels in Spain) or when advertisers and consumers reside in different jurisdictions (e.g. advertisers registered in Ireland target ads to users in the U.K.) Throughout the analysis, we assume that users are immobile, either because their moving costs are too high or because they have already moved before the platform chooses its prices and the cost of relocation is high.

\subsection{Utilities of users and pre-tax profit of the platform}

A monopolistic platform connects users from two jurisdictions $A$ and $B$. We let $x_{A}$ and $x_{B}$ denote the total number of users in jurisdictions $A$ and $B$ respectively. The platform follows a business model whereby all users pay a fixed fee to access the platform. The platform can discriminate according to the residence of users, charging a fee $p_{A}$ for users in jurisdiction $A$ and 
a fee $p_{B}$ for users in jurisdiction $B$. The volume of use of the platform is supposed to be fixed and identical across users.

In each jurisdiction, the utility of users is the sum of two components: an idiosyncratic utility for the platform, which is heterogeneous across users, and a positive externality term which depends on the number of other users in the platform, distinguishing between users in jurisdictions $A$ and $B$. Formally,

$$
\begin{aligned}
& U_{A}=\theta_{A}+u_{A}\left(x_{A}, x_{B}\right)-p_{A} \\
& U_{B}=\theta_{B}+u_{B}\left(x_{A}, x_{B}\right)-p_{B}
\end{aligned}
$$

where $\theta_{A}$ is distributed according to a continuous distribution with full support $F_{A}$ on $[\underline{\theta}, \bar{\theta}]$, and $\theta_{B}$ is distributed according to a continuous distribution with full support $F_{B}$ on $[\eta, \bar{\eta}]$.

We assume that externalities across jurisdictions are always nonnegative : $u_{A}$ is weakly increasing in $x_{B}$ and $u_{B}$ is weakly increasing in $x_{A}$. Externalities arising from the participation of users from the same jurisdiction can either be positive or negative. To illustrate, we map out the model with some examples.

1- Peer-to-peer platforms: The users only care about a weighted total number of users: The externality for users in $A$ and in $B$ are described by weakly increasing functions $u_{A}\left(x_{A}+b x_{B}\right)$ and $u_{B}\left(a x_{A}+x_{B}\right)$, where $a$ and $b$ represents the weight placed on users from abroad. There are positive externalities both across and within jurisdictions.

2- Social media and search engines. Users are located in $A$ and advertisers in $B$. Users of a social media are positively affected by the number of users of the media: there are positive externalities within $A$. If users do not draw any benefit or cost from advertising, there are no externalities from $B$ to $A$ : The externality for users in $A$ is described by an increasing function $u_{A}\left(x_{A}\right)$. Advertisers, benefit from the number of users, but compete with other advertisers. The externality $u_{B}\left(x_{A}, x_{B}\right)$ is weakly increasing in $x_{A}$ and weakly decreasing in $x_{B}$. Notice that externalities only flow from jurisdiction $A$ to jurisdiction $B$. Search engines follow a similar pattern, but users do not draw benefits from the presence of other users: $u_{A}$ is constant, while $u_{B}\left(x_{A}, x_{B}\right)$ is weakly increasing in $x_{A}$ and weakly decreasing in $x_{B}$.

3 - Online intermediaries. Buyers reside in jurisdiction $A$ and sellers in jurisdiction $B$. There are positive externalities across jurisdictions but negligible externalities within each jurisdiction: they are described by weakly increasing functions $u_{A}\left(x_{B}\right)$ and $u_{B}\left(x_{A}\right)$.

We now derive the demand associated to the fees $\left(p_{A}, p_{B}\right)$. Let $x_{A}$ and $x_{B}$ be the common expectation of every user over the number of users in the two jurisdictions. We compute the value of the user in jurisdiction $A$ who is indifferent between buying access to the platform or not. This value is given by

$$
\widehat{\theta_{A}}=p_{A}-u_{A}\left(x_{A}, x_{B}\right) .
$$

provided that $p_{A}-u_{A}\left(x_{A}, x_{B}\right)$ belongs to the support of $F_{A}$; otherwise $\widehat{\theta_{A}}$ will be equal to one of the extreme values $\underline{\theta}$ (if the market is covered) or $\bar{\theta}$ (if no user accesses the platform). We can similarly compute the value of the indifferent user in jurisdiction $B$. The two jurisdictions may 
have different sizes. We normalize the measure of users in jurisdiction $B$ to 1 , and let $s$ denote the measure of users in jurisdiction $A$. Assuming that expectations are rational, the demand thus satisfies

$$
x_{A}=s\left(1-F_{A}\left(p_{A}-u_{A}\left(x_{A}, x_{B}\right)\right),\right.
$$

Similarly,

$$
x_{B}=1-F_{B}\left(p_{B}-u_{B}\left(x_{A}, x_{B}\right)\right) .
$$

There is a one-to-one relationship between the prices chosen by the monopolistic platform $p_{A}$ and $p_{B}$ and the number of users $x_{A}$ and $x_{B}$. As argued by Weyl (2010), it will prove easier to write the profit in terms of numbers of users instead of prices. ${ }^{4}$ The interpretation is that the platform chooses $x_{A}$ and $x_{B}$, knowing the prices for which the numbers of users will be $x_{A}$ and $x_{B}$. From the computations above, the prices are given by ${ }^{5}$

$$
\begin{aligned}
& P_{A}\left(x_{A}, x_{B}\right)=u_{A}\left(x_{A}, x_{B}\right)+F_{A}^{-1}\left(1-\frac{x_{A}}{s}\right), \\
& P_{B}\left(x_{A}, x_{B}\right)=u_{B}\left(x_{A}, x_{B}\right)+F_{B}^{-1}\left(1-x_{B}\right) .
\end{aligned}
$$

Because externalities are positive, the price $P_{A}\left(x_{A}, x_{B}\right)$ is increasing in $x_{B}$. We suppose that externalities are not too strong, to guarantee that the price function $P_{A}\left(x_{A}, x_{B}\right)$ is decreasing in $x_{A}$. This assumption is satisfied if externalities are non-positive within $A$ ( $u_{A}$ is decreasing in $\left.x_{A}\right)$. It is also satisfied when externalities are positive but the marginal effect of an increase in $x_{A}$ on $u_{A}$ is sufficiently small relative to the marginal effect on the distribution $F\left(\partial u_{A} / \partial x_{A} F^{\prime}(1-\right.$ $\left.\left.x_{A}\right) \leq 1\right)$ Similarly, in jurisdiction $B$ the price function $P_{B}\left(x_{A}, x_{B}\right)$ is increasing in $x_{A}$ and assumed to be decreasing in $x_{B}$.

The user surplus in jurisdiction $A$ is computed as

$$
\begin{aligned}
C S_{A} & =\int_{p_{A}-u\left(x_{A}, x_{B}\right)}^{\underline{\theta}}\left[\theta+u_{A}\left(x_{A}, x_{B}\right)-p_{A}\right] f(\theta) d \theta, \\
& =\int_{F_{A}^{-1}\left(1-x_{A}\right)}^{\underline{\theta}}\left[\theta-F_{A}^{-1}\left(1-x_{A}\right)\right] f(\theta) d \theta
\end{aligned}
$$

Taking into account the participation decision of the users, the user surplus in jurisdiction $A$ can be written as a function only of the number of participants in jurisdiction $A, x_{A}$. Furthermore, it is easy to check that

\footnotetext{
${ }^{4}$ Such a construction does not work for competitive platforms where competition in prices (Bertrand) leads to different results than competition in quantities (Cournot). See Belleflamme and Toulemonde (2016) for a study of two platforms competing in prices.

${ }^{5}$ The price functions are akin to inverse demand functions, with one caveat: due to coordination issues, a given couple of prices $\left(p_{A}, p_{B}\right)$ could lead to different demands. In that case we select the largest demands.
} 


$$
\begin{aligned}
\frac{\partial C S_{A}}{\partial x_{A}} & =\int_{F_{A}^{-1}\left(1-x_{A}\right)}^{\underline{\theta}}\left[\frac{1}{f\left[F_{A}^{-1}\left(1-x_{A}\right)\right]} d \theta,\right. \\
& =\frac{1-F_{A}^{-1}\left(1-x_{A}\right)}{f\left[F_{A}^{-1}\left(1-x_{A}\right)\right]} \\
& >0
\end{aligned}
$$

Hence, as intuition suggests, an increase in the number of participants $x_{A}$ results in an increase in user surplus. Similarly, we obtain

$$
C S_{B}=\int_{F_{B}^{-1}\left(1-x_{B}\right)}^{\underline{\theta}}\left[\theta-F_{B}^{-1}\left(1-x_{B}\right)\right] f(\theta) d \theta,
$$

and

$$
\frac{\partial C S_{B}}{\partial x_{B}}=\frac{1-F_{B}^{-1}\left(1-x_{B}\right)}{f\left[F_{B}^{-1}\left(1-x_{B}\right)\right]}>0 .
$$

We suppose, following empirical evidence, that the operating costs of the platform are negligible so that the pre-tax profit in each jurisdiction is given by

$$
\begin{aligned}
V_{A} & =x_{A} P_{A}\left(x_{A}, x_{B}\right) \\
V_{B} & =x_{B} P_{B}\left(x_{A}, x_{B}\right)
\end{aligned}
$$

and the total pre-tax profit as

$$
V=V_{A}+V_{B} .
$$

The strategy of the platform depends on how marginal revenues in a jurisdiction depend on the number of users in the other jurisdiction. In order to compute the optimal choices of the platform, we need to assess the signs of the cross-partial derivatives $\frac{\partial^{2} V_{A}}{\partial x_{A} \partial x_{B}}$ and $\frac{\partial^{2} V_{B}}{\partial x_{A} \partial x_{B}}$. We compute

$$
\frac{\partial^{2} V_{A}}{\partial x_{A} \partial x_{B}}=\frac{\partial P_{A}}{\partial x_{B}}+x_{A} \frac{\partial^{2} P_{A}}{\partial x_{A} \partial x_{B}} .
$$

The first term, $\frac{\partial P_{A}}{\partial x_{B}}$, measures the positive marginal effect of the number of users in $B$ on the price in $A$. The cross-derivative is positive when this positive marginal effect does not decrease too fast with $x_{A}$, more precisely when the elasticity of $\frac{\partial P_{A}}{\partial x_{B}}$ with respect to $x_{A}$ is larger than -1 .

We relate this condition to the externalities of users in jurisdiction $A, u_{A}$. Using (1), we obtain

$$
\frac{\partial^{2} V_{A}}{\partial x_{A} \partial x_{B}}=\frac{\partial u_{A}}{\partial x_{B}}+x_{A} \frac{\partial^{2} u_{A}}{\partial x_{A} \partial x_{B}} .
$$

The first term $\frac{\partial u_{A}}{\partial x_{B}}$ is positive due to positive cross-externalities across jurisdictions. The second term may be positive or negative. The sum of the two terms is positive when the marginal 
cross-externality in market $A, \frac{\partial u_{A}}{\partial x_{B}}$ increases, or decreases with the number of users in $A$ with an elasticity less than 1 . It is negative when the marginal cross-externality $\frac{\partial u_{A}}{\partial x_{B}}$ decreases with the number of users in $A$ at a very fast rate, with an elasticity greater than 1.

We say that the two markets are complements when both $\frac{\partial^{2} V_{A}}{\partial x_{A} \partial x_{B}}$ and $\frac{\partial^{2} V_{B}}{\partial x_{A} \partial x_{B}}$ are nonnegative. In the opposite case, when both $\frac{\partial^{2} V_{A}}{\partial x_{A} \partial x_{B}}$ and $\frac{\partial^{2} V_{B}}{\partial x_{A} \partial x_{B}}$ are non-positive, we say that the two markets are substitutes.

The case of market complements is probably the most natural case. Markets are complements whenever the cross-derivatives $\frac{\partial^{2} u_{A}}{\partial x_{A} \partial x_{B}}$ and $\frac{\partial^{2} u_{B}}{\partial x_{A} \partial x_{B}}$ are non-negative. This includes the case where $u_{A}$ and $u_{B}$ are linear and the cross-derivatives vanish. When there are no externalities from users in the same jurisdiction $\left(u_{A}\right.$ does not depend on $x_{A}$ and $u_{B}$ does not depend on $\left.x_{B}\right)$, the cross-derivatives are also equal to zero, so markets are complements. In the peer-to-peer model, where $u_{A}\left(x_{A}, x_{B}\right)=u\left(x_{A}+b x_{B}\right)$, markets are complements whenever the elasticity of the function $u$ is smaller than $1 .^{6}$

\subsection{Separate Accounting and Formula Apportionment}

We suppose that the two jurisdictions charge corporate income tax rates $t_{A}$ and $t_{B}$. We consider two regimes of profit-sharing. Under Separate Accounting (SA), the platform pays taxes according to the profit declared in each jurisdiction. The post-tax profit of the platform is then given by

$$
\Pi=\left(1-t_{A}\right) V_{A}+\left(1-t_{B}\right) V_{B} .
$$

and the fiscal revenues of the two jurisdictions are computed as

$$
\begin{aligned}
& R_{A}=t_{A} V_{A}, \\
& R_{B}=t_{B} V_{B} .
\end{aligned}
$$

Under Formula Apportionment (FA), the total profit of the platform, $V$ is attributed to each jurisdiction using the ratio of users, so that the post-tax profit is given by

$$
\Pi=V\left[1-t_{A} \frac{x_{A}}{x_{A}+x_{B}}-t_{B} \frac{x_{B}}{x_{A}+x_{B}}\right],
$$

and the fiscal revenues of the two jurisdictions are computed as

$$
\begin{aligned}
R_{A} & =t_{A} V \frac{x_{A}}{x_{A}+x_{B}}, \\
R_{B} & =t_{B} V \frac{x_{B}}{x_{A}+x_{B}} .
\end{aligned}
$$

\footnotetext{
${ }^{6}$ To see this, notice that

$$
\frac{\partial^{2} V_{A}}{\partial x_{A} \partial x_{B}}=u^{\prime}\left(x_{A}+b x_{B}\right)+x_{A} u^{\prime \prime}\left(x_{A}+b x_{B}\right)
$$

Since $u$ is concave,

$$
\frac{\partial^{2} V_{A}}{\partial x_{A} \partial x_{B}} \geq u^{\prime}\left(x_{A}+b x_{B}\right)+\left(x_{A}+b x_{B}\right) u^{\prime \prime}\left(x_{A}+b x_{B}\right)
$$

Thus the cross-derivative is positive whenever the elasticity of $u^{\prime},-x \frac{u^{\prime \prime}}{u^{\prime}}$, is smaller than 1 .
} 
Formula Apportionment only makes sense when the apportionment key uses the same type of users in the two jurisdictions. Hence FA is an appropriate profit-sharing regime for peer-to-peer platforms, but not for two-sided platforms, where different types of users reside in different jurisdictions.

When the corporate tax rates are equal, the platform chooses to maximize the ex-ante profit $V$ under both regimes whatever the common level of the tax. From standard arguments, the firm thus chooses the optimal number of users. Let $x_{A}^{*}$ and $x_{B}^{*}$ denote these levels. When the corporate tax levels $t_{A}$ and $t_{B}$ differ, the platform has an incentive to distort the number of users away from the optimum, in order to reduce its tax bill in the high tax jurisdiction. Even in the absence of transfer pricing, the platform can exploit the positive externalities between markets to shift profit to the low tax jurisdiction.

\section{Separate accounting}

Our objective in this Section is to compute the optimal choices of the platform under SA for a fixed choice of tax rates $\left(t_{A}, t_{B}\right)$ and analyze the comparative statics effects of an increase in one of the corporate tax rates, $t_{A}$. This comparative statics exercise will also allow us to describe distortions from the optimum in high tax and low tax jurisdictions, starting from a situation where the two jurisdictions set equal tax rates, and the platform chooses the optimal values $x_{A}^{*}$ and $x_{B}^{*}$.

Because of externalities across jurisdictions, the optimal numbers of users in jurisdictions $A$ and $B$ are interdependent. Even though we consider the optimization problem of a single firm, we introduce, by similarity with strategic games, two "reaction" functions $\phi_{A}$ and $\phi_{B}$ to denote the optimal number of users in jurisdictions $A$ and $B$ as a function of the number of users in the other jurisdiction. Formally, $\phi_{A}\left(x_{B} ; t_{A}, t_{B}\right)$ is the value $x_{A}$ that maximizes the platform's profit given $x_{B}$ and the tax rates $\left(t_{A}, t_{B}\right)$ and $\phi_{B}\left(x_{A} ; t_{A}, t_{B}\right)$ the value $x_{B}$ that maximizes the platform's profit given $x_{A}$ and the tax rates $\left(t_{A}, t_{B}\right)$. The optimal numbers of users for the platform are obtained at the intersection of these two reaction functions, denoted $\left(X_{A}, X_{B}\right)$, as in a game between two players:

$$
X_{A}\left(t_{A}, t_{B}\right)=\phi_{A}\left(X_{B}\left(t_{A}, t_{B}\right) ; t_{A}, t_{B}\right) \text { and } X_{B}\left(t_{A}, t_{B}\right)=\phi_{B}\left(X_{A}\left(t_{A}, t_{B}\right) ; t_{A}, t_{B}\right) .
$$

In order to understand the platform's incentives to shift profit better, we compute the comparative statics effects of a change in the corporate tax rate $t_{A}$ on the optimal choices of the platform, i.e., $\frac{d X_{A}}{d t_{A}}$ and $\frac{d X_{B}}{d t_{A}}$ when these are well defined. We assume that the profit's platform is concave in $x_{A}$ and $x_{B}$ so that the optimal interior values are characterized by the first-order conditions:

$$
\begin{aligned}
& x_{A}=\phi_{A}\left(x_{B} ; t_{A}, t_{B}\right) \text { if } \frac{\partial \Pi}{\partial x_{A}}=\left(1-t_{A}\right) \frac{\partial V_{A}}{\partial x_{A}}\left(x_{A}, x_{B}\right)+\left(1-t_{B}\right) \frac{\partial V_{B}}{\partial x_{A}}\left(x_{A}, x_{B}\right)=0, \\
& x_{B}=\phi_{B}\left(x_{A} ; t_{A}, t_{B}\right) \text { if } \frac{\partial \Pi}{\partial x_{B}}=\left(1-t_{A}\right) \frac{\partial V_{A}}{\partial x_{B}}\left(x_{A}, x_{B}\right)+\left(1-t_{B}\right) \frac{\partial V_{B}}{\partial x_{B}}\left(x_{A}, x_{B}\right)=0
\end{aligned}
$$


and

$$
\begin{aligned}
\frac{d X_{A}}{d t_{A}}=\frac{\frac{\partial \phi_{A}}{\partial t_{A}}+\frac{\partial \phi_{A}}{\partial x_{B}} \frac{\partial \phi_{B}}{\partial t_{A}}}{1-\frac{\partial \phi_{A}}{\partial x_{B}} \frac{\partial \phi_{B}}{\partial x_{A}}} \\
\frac{d X_{B}}{d t_{A}}=\frac{\frac{\partial \phi_{B}}{\partial t_{A}}+\frac{\partial \phi_{B}}{\partial x_{A}} \frac{\partial \phi_{A}}{\partial t_{A}}}{1-\frac{\partial \phi_{A}}{\partial x_{B}} \frac{\partial \phi_{B}}{\partial x_{A}}} .
\end{aligned}
$$

We observe that the optimal number of users in the two jurisdictions $X_{A}$ and $X_{B}$ vary with the corporate tax rates. Using the first-order conditions (4) and (5), we obtain:

$$
\begin{gathered}
\frac{\partial \phi_{A}}{\partial t_{A}}=\frac{\frac{\partial V_{A}}{\partial x_{A}}}{\frac{\partial^{2} \Pi}{\partial x_{A}^{2}}} \quad \text { and } \frac{\partial \phi_{B}}{\partial t_{A}}=\frac{\frac{\partial V_{A}}{\partial x_{B}}}{\frac{\partial^{2} \Pi}{\partial x_{B}^{2}}} \\
\frac{\partial \phi_{A}}{\partial x_{B}}=-\frac{\frac{\partial^{2} \Pi}{\partial x_{A} x_{B}}}{\frac{\partial^{2} \Pi}{\partial x_{A}^{2}}} \quad \text { and } \quad \frac{\partial \phi_{B}}{\partial x_{A}}=-\frac{\frac{\partial^{2} \Pi}{\partial x_{A} x_{B}}}{\frac{\partial^{2} \Pi}{\partial x_{B}^{2}}} \\
\text { where } \frac{\partial^{2} \Pi}{\partial x_{A} x_{B}}=\left(1-t_{A}\right) \frac{\partial^{2} V_{A}}{\partial x_{A} \partial x_{B}}+\left(1-t_{B}\right) \frac{\partial^{2} V_{B}}{\partial x_{A} \partial x_{B}}
\end{gathered}
$$

Due to the concavity of profit, the product $\frac{\partial \phi_{A}}{\partial x_{B}} \frac{\partial \phi_{B}}{\partial x_{A}}$ is less than 1. Hence, from (6) and (7), the signs of the effect of a change in $t_{A}$ on the number of users in jurisdiction $A$ and $B$ are respectively the same as the signs of

$$
\frac{\partial \phi_{A}}{\partial t_{A}}+\frac{\partial \phi_{A}}{\partial x_{B}} \frac{\partial \phi_{B}}{\partial t_{A}} \text { and } \frac{\partial \phi_{B}}{\partial t_{A}}+\frac{\partial \phi_{B}}{\partial x_{A}} \frac{\partial \phi_{A}}{\partial t_{A}} .
$$

We can thus decompose the effect of an increase in the tax rate $t_{A}$ on the number of users in jurisdiction $i=A, B$ into (i) a direct effect $\frac{\partial \phi_{i}}{\partial t_{A}}$ and (ii) an indirect effect, $\frac{\partial \phi_{i}}{\partial x_{j}} \frac{\partial \phi_{j}}{\partial t_{A}}$. The direct effect measures how the change in the corporate tax rate $t_{A}$ affects the choice of the platform in jurisdiction $i, X_{i}$, assuming the number of users $x_{j}$ in the other jurisdiction unchanged. The indirect effect measures how the change in the corporate tax rate $t_{A}$ affects $X_{i}$ through a reaction to the change in the number $x_{j}$ of users in the other jurisdiction. We sign these two effects separately.

Consider first the direct effects, $\frac{\partial \phi_{A}}{\partial t_{A}}$ and $\frac{\partial \phi_{B}}{\partial t_{A}}$, given in (8). We claim that

The direct effect of an increase in the corporate tax rate $t_{A}$ is positive on the number of users in jurisdiction $A$ and negative on the number of users in jurisdiction $B$.

To show this, observe first that, by concavity, $\frac{\partial^{2} \Pi}{\partial x_{A}^{2}}$ and $\frac{\partial^{2} \Pi}{\partial x_{B}^{2}}$ are both negative. Because externalities across jurisdictions are positive, $\frac{\partial V_{B}}{\partial x_{A}}=x_{B} \frac{\partial P_{B}}{\partial x_{A}} \geq 0$ and $\frac{\partial V_{A}}{\partial x_{B}}=x_{A} \frac{\partial P_{A}}{\partial x_{B}} \geq 0$, we immediately obtain from the first order conditions on profit maximization

$$
\frac{\partial V_{A}}{\partial x_{A}}=-\frac{1-t_{B}}{1-t_{A}} \frac{\partial V_{B}}{\partial x_{A}} \leq 0 \text { and } \frac{\partial V_{B}}{\partial x_{B}}=-\frac{1-t_{A}}{1-t_{B}} \frac{\partial V_{A}}{\partial x_{B}} \leq 0
$$


implying that $\frac{\partial \phi_{A}}{\partial t_{A}} \geq 0$ and $\frac{\partial \phi_{B}}{\partial t_{A}} \leq 0$ from (8). The inequalities are strict when the externalities are strictly positive.

To understand the signs of the direct effects, recall that, when $t_{A}$ increases, the platform has an incentive to shift profit from jurisdiction $A$ to jurisdiction $B$. To do so, should the platform increase or decrease the number of users in jurisdiction $A$ ? Because profit is concave, consider two values $x_{A}^{\prime}$ and $x_{A}^{\prime \prime}$ that result in the same profit $V_{A}$, but such that $x_{A}^{\prime}<x_{A}<x_{A}^{\prime \prime}$. By choosing the higher value $x_{A}^{\prime \prime}$, through the positive externalities across markets, the platform weakly increases the profit $V_{B}$ in the lower-tax jurisdiction. Hence, $x_{A}^{\prime \prime}$ is always a better choice than $x_{A}^{\prime}$, and the platform has an incentive to increase the number of users in jurisdiction $A$. By the same reasoning, consider two values $x_{B}^{\prime}<x_{B}<x_{B}^{\prime \prime}$ which result in the same profit $V_{B}$. By choosing the lower value $x_{B}^{\prime}$, through positive externalities, the platform reduces the profit $V_{A}$ in the higher-tax jurisdiction. Hence in order to shift profit away from the higher-tax jurisdiction, the platform has an incentive to choose $x_{B}^{\prime}$, reducing the number of users in the lower-tax jurisdiction.

Consider now the indirect effects, $\frac{\partial \phi_{A}}{\partial x_{B}} \frac{\partial \phi_{B}}{\partial t_{A}}$ and $\frac{\partial \phi_{B}}{\partial x_{A}} \frac{\partial \phi_{A}}{\partial t_{A}}$ generated by the marginal reactions of the demand in one jurisdiction to the demand in the other. While we have established above the signs of $\frac{\partial \phi_{B}}{\partial t_{A}}$ and $\frac{\partial \phi_{A}}{\partial t_{A}}$, we still need to study the signs of the derivatives of the reaction functions, $\frac{\partial \phi_{A}}{\partial x_{B}}$ and $\frac{\partial \phi_{B}}{\partial x_{A}}$. From (9) the signs generated by these marginal reactions, $\frac{\partial \phi_{A}}{\partial x_{B}}$ and $\frac{\partial \phi_{B}}{\partial x_{A}}$, are both identical to the sign of the cross-derivative $\frac{\partial^{2} \Pi}{\partial x_{A} \partial x_{B}}$, which in turn, from (10), depends on the cross-derivatives $\frac{\partial^{2} V_{A}}{\partial x_{A} \partial x_{B}}$ and $\frac{\partial^{2} V_{B}}{\partial x_{A} \partial x_{B}}$. If the markets are complements, both cross-derivatives are positive: the reaction functions are increasing. When the number of users in one jurisdiction increases, the optimal number of users in the other jurisdiction increases. If, on the other hand, the markets are substitutes, both cross-derivatives are negative and the two reaction functions are decreasing. An increase in the number of users in one jurisdiction leads the platform to decrease the number of users in the other jurisdiction. Accounting for both direct and indirect effects, we thus assert the following.

Proposition 1 Suppose that markets are substitutes. Then an increase in the corporate tax rate $t_{A}$ always results in an increase in the number of users in jurisdiction $A$ and a decrease in the number of users in jurisdiction B. Suppose that markets are complements, then an increase in the corporate tax rate $t_{A}$ never results in a decrease in the number of users in jurisdiction $A$ together with an increase in the number of users in jurisdiction $B$.

Starting from equal tax levels, for which the optimal levels $x_{A}^{*}, x_{B}^{*}$ are chosen, the following result immediately follows.

Corollary 1 Let $t_{A} \geq t_{B}$. Suppose that markets are substitutes. Then the number of users in jurisdiction $A$ is greater than the optimal number of users $x_{A}^{*}$ and the number of users in jurisdiction $B$ is lower than the optimal number of users $x_{B}^{*}$. Suppose that markets are complements. Then the number of users in jurisdiction $A$ is higher than the optimal number of users $x_{A}^{*}$ or/and the number of users in jurisdiction $B$ is lower than the optimal number of isers $x_{B}^{*}$. 

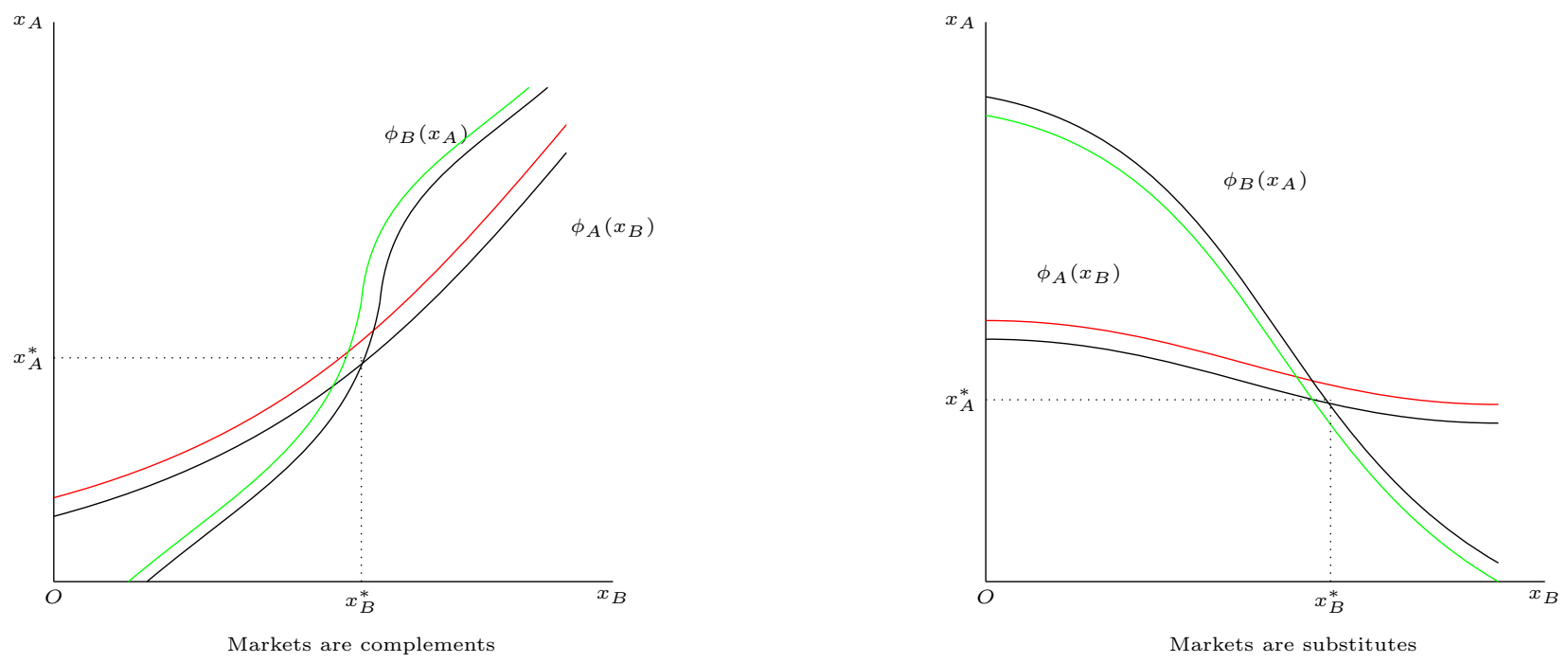

Figure 1: Effect of an increase in $t_{A}$ under SA

The direct effects result in an increase in $x_{A}$ and a decrease in $x_{B}$. When markets are substitutes, the direct and indirect effects reinforce each other: the decrease in $x_{B}$ induces an additional increase in $x_{A}$ and a decrease in $x_{B}$, which induces further reactions in the same directions. When markets are complements, the direct and indirect effects work in opposite directions. The effect of a change in the corporate tax rate of the platform then depends on the relative magnitude of the direct and indirect effects. However, due to the concavity of the profit, the indirect effect cannot outweigh the direct effect on both markets, as proved in the Appendix. Apart from this impossible case, an increase in $t_{A}$ may result in any possible effects on the number of users in both jurisdictions, as we will see in the next Section.

Figure 1 illustrates the effect of a change in the corporate tax rate $t_{A}$ on the two reaction functions $\phi_{A}$ and $\phi_{B}$ when markets are complements (left panel) and substitutes (right panel). The curves in black depict the functions $\phi_{A}$ and $\phi_{B}$ when the tax rates are identical. The intersection of the two curves gives the optimal numbers of users. The curves in red and green describe the same functions following an increase in $t_{A}$. The new choices of the platform are given by the intersection of the red and green curves. In both cases, an increase in $t_{A}$ leads to an increase in $\phi_{A}$ and a decrease in $\phi_{B}$. When markets are complements, the direct and indirect effects work in opposite directions: the direct effect of an increase in $t_{A}$ on $x_{A}$ (respectively $x_{B}$ ) is positive (respectively negative), whereas the indirect effect is negative (respectively positive). Which of the two dominates depends on the exact specifications of the model. When, on the other hand, markets are substitutes, direct and indirect effects work in the same direction. An increase in $t_{A}$ unambiguously results in an increase in the number of users in jurisdiction $A$ and a decrease in the number of users in jurisdiction B.

When the reaction functions are decreasing or when the direct effect dominates the indirect effect, an increase in $t_{A}$ results in an increase in $x_{A}$ and a decrease in $x_{B}$. Hence the price in 
market $A, P_{A}$ goes down while the price in market $B, P_{B}$, goes up. When the tax rate $t_{A}$ is sufficiently high, market $A$ will end up being covered, and the fee $p_{A}$ will become negligible (equal to the externalities generated by users on market $B$ ). The platform eventually chooses to extract revenues from users in the lower-tax jurisdiction, while charging the minimal fee to participants in the higher-tax jurisdiction. This behavior is reminiscent of the actual business model of many platforms, such as search engines and digital social networks, who choose to attract users (from high tax jurisdictions) on one side of the platform with a free service and charge fees to advertisers (located in low tax jurisdictions) on the other side of the platform.

We also observe that an increase in the corporate tax rate $t_{A}$ always results in a reduction in the profit of the platform. By the envelope theorem, only the direct effect of $t_{A}$ on the post-tax profit matters, and this direct effect is given by $\frac{\partial \Pi}{\partial t_{A}}=-V_{A}$ and is always negative.

Consider next the effect of an increase in $t_{A}$ on the tax revenues of jurisdiction $A$,

$$
\begin{aligned}
\frac{\partial R_{A}}{\partial t_{A}} & =V_{A}+\frac{\partial V_{A}}{\partial t_{A}}, \\
& =V_{A}+\frac{\partial V_{A}}{\partial x_{A}} \frac{\partial X_{A}}{\partial t_{A}}+\frac{\partial V_{A}}{\partial x_{B}} \frac{\partial X_{B}}{\partial t_{A}}
\end{aligned}
$$

An increase in the tax rate $t_{A}$ has two effects on tax revenues: a positive direct effect (measured by the first term $V_{A}$ ) and an effect on the tax base (measured by the second term $\left.\frac{\partial V_{A}}{\partial x_{A}} \frac{\partial X_{A}}{\partial t_{A}}+\frac{\partial V_{A}}{\partial x_{B}} \frac{\partial X_{B}}{\partial t_{A}}\right)$. When markets are substitutes, or when markets are complements and the direct effect dominates the indirect effect, $X_{A}$ is increasing and $X_{B}$ decreasing in $t_{A}$, so that the effect on the tax base is negative. An increase in the corporate tax rate then has an ambiguous effect on the tax revenues of jurisdiction A.

Similarly, we compute the effect of an increase in $t_{A}$ on the tax revenues of jurisdiction $B$ as

$$
\frac{\partial R_{B}}{\partial t_{A}}=\frac{\partial V_{B}}{\partial t_{A}}=\frac{\partial V_{B}}{\partial x_{A}} \frac{\partial X_{A}}{\partial t_{A}}+\frac{\partial V_{B}}{\partial x_{B}} \frac{\partial X_{B}}{\partial t_{A}} .
$$

The positive effect disappears and the only effect is the effect on the tax base. When the direct effect dominates, $X_{A}$ is increasing and $X_{B}$ decreasing in $t_{A}$, so that the effect on the tax base is positive. An increase in the corporate tax rate in jurisdiction $A$ increases the tax base in jurisdiction $B$, resulting in an increase in the tax revenues of jurisdiction $B$.

We now investigate in detail the magnitude of the direct and indirect effects in two simple situations: when externalities are one-sided and when the two jurisdictions are symmetric and corporate tax rates are initially set at the same rate $t$.

\subsection{One-sided externalities}

We first suppose that externalities are one-sided so that only one type of users experiences positive externalities from the presence of the other users. For example, in search engines, advertisers benefit from the presence of a large number of users, but users are unlikely to benefit from a large number of users (in particular when they are averse to advertising). We first consider the case where users in the higher-tax jurisdiction $A$ do not benefit from the presence of users 
in jurisdiction $B, \frac{\partial P_{A}}{\partial x_{B}}=0$. As there is no effect of $x_{B}$ on users in jurisdiction $A, \frac{\partial V_{A}}{\partial x_{B}}=0$. This implies that the optimal choice of the platform in jurisdiction $B$ is given by $\frac{\partial V_{B}}{\partial x_{B}}=0$ (from (11)), and becomes independent of the corporate tax rates $t_{A}$ and $t_{B}$. A change in the corporate tax rate $t_{A}$ does not induce any direct distortion on the optimal number of users in jurisdiction $B$, $\frac{\partial \phi_{B}}{\partial t_{A}}=0$. A change in the tax rate $t_{A}$ then only has a direct effect on the number of users in jurisdiction $A$, and only has an indirect effect only on the number of users in jurisdiction $B$. We conclude that an increase in the corporate tax rate $t_{A}$ always results in an increase in the number of users in jurisdiction $A$, an increase in the number of users in jurisdiction $B$ when markets are complements, and a decrease in the number of users in jurisdiction $B$ when markets are substitutes. Furthermore as $\frac{\partial V_{B}}{\partial x_{B}}=0, \frac{\partial V_{B}}{\partial x_{A}}>0$ and $\frac{\partial X_{A}}{\partial t_{A}}>0$, the tax revenues of jurisdiction $B$ are increasing in $t_{A}$.

Next, suppose that users in the lower-tax jurisdiction $B$ do not benefit from the presence of users in jurisdiction $A$ on the platform, $\frac{\partial P_{B}}{\partial x_{A}}=0$. By a similar reasoning, the optimal choice of the platform in jurisdiction $A$ is given by $\frac{\partial V_{A}}{\partial x_{A}}=0$ and is independent of the tax rate $t_{A}$. An increase in the corporate tax rate $t_{A}$ only has a direct effect on the number of users in jurisdiction $B$, and an indirect effect on the number of users in jurisdiction $A$. An increase in the corporate tax rate $t_{A}$ thus always results in a decrease in the number of users in jurisdiction $B$, a decrease in the number of users in jurisdiction $A$ when markets are complements, and an increase in the number of users in jurisdiction $A$ when markets are substitutes. Furthermore, as $\frac{\partial V_{B}}{\partial x_{A}}=0, \frac{\partial V_{B}}{\partial x_{B}}<0$ (from (11)) and $\frac{\partial X_{B}}{\partial t_{A}}<0$, the tax revenues of jurisdiction $B$ are increasing in $t_{A}$. We summarize in the following Proposition

Proposition 2 (One-sided) Suppose that externalities only flow from market $A$ to market $B$. $A n$ increase in the corporate tax rate $t_{A}$ always results in an increase in the number of users in jurisdiction $A$. It results in an increase in the number of users in jurisdiction $B$ if markets are complements and a decrease in the number of users in jurisdiction $B$ if markets are substitutes. Conversely, if externalities only flow from market $B$ to market $A$, an increase in the corporate tax rate $t_{A}$ always results in a decrease in the number of users in jurisdiction $B$. It results in a decrease in the number of users in jurisdiction $A$ if markets are complements and an increase in the number of users in jurisdiction $A$ if markets are substitutes. In both cases, the tax revenues of jurisdiction $B$ are increasing in $t_{A}$ while the effect of an increase in $t_{A}$ on the tax revenues of jurisdiction $A$ is ambiguous.

Proposition 2 shows that if the side caring about the presence of users on the other side is located in the higher-tax jurisdiction, in the more plausible case of complements, the platform has an incentive to increase the number of users (and reduce the price) in both jurisdictions. If however, as is the case for example for Google in Europe, advertisers who care about the presence of users on the other side are located in a low tax jurisdiction like Ireland, the platform has an incentive to reduce the number of users (and increase prices) in both jurisdictions. As corporate tax rates in European jurisdictions (outside the low tax jurisdictions like Ireland and Luxembourg) have experienced a significant decrease over the past decades, the model predicts that internet platforms like Google and Facebook should have responded by an increase both in the number of users and advertisers 


\subsection{Symmetric jurisdictions}

We next consider a situation where demands are symmetric, $P_{A}\left(x_{A}, x_{B}\right)=P_{B}\left(x_{B}, x_{A}\right)$ for all $x_{A}, x_{B}$, and tax rates are identical, $t_{A}=t_{B}=t$. This assumption captures peer-to-peer markets where externalities are balanced and the sizes of the markets are identical. This corresponds to peer-to-peer platforms operating in jurisdictions of similar size. By symmetry, when the tax rates are identical, the direct effects of an increase in the corporate tax rate $t_{A}$ on the number of users in the two jurisdictions have opposite signs but the same magnitude. Furthermore, concavity implies that the slope of the reaction functions $\phi_{A}\left(x_{B} ; t_{A}, t_{B}\right)$ and $\phi_{B}\left(x_{A} ; t_{A}, t_{B}\right)$ are smaller than 1. Hence when markets are complements, the direct effect of a change in the corporate tax rate $t_{A}$ always dominates the indirect effect. When markets are substitutes, the two effects always work in the same direction. We obtain the following Proposition

Proposition 3 (Symmetric) Suppose that jurisdictions are symmetric and $t_{A}=t_{B}=t$. $A$ small increase in the corporate tax rate $t_{A}$ always results in an increase in the number of users in jurisdiction $A$ and a decrease in the number of users in jurisdiction B. Hence prices in jurisdiction $A$ decrease, prices in jurisdiction $B$ increase, tax revenues in jurisdiction $B$ increase while the effect on tax revenues in jurisdiction $A$ is ambiguous.

Proposition 3 shows that when similar jurisdictions apply similar corporate tax rates on a digital platform, a marginal increase in the corporate tax rate of one jurisdiction results in an increase in the number of users in that jurisdiction and a reduction in the number of users in the other jurisdiction. This in turn has an immediate effect on prices, yielding lower prices in the jurisdiction with a higher tax rate and higher prices in the jurisdiction with lower tax rates. The tax base will be shifted to the low tax jurisdiction, so that tax revenues in that jurisdiction increase. Hence, per-to-peer platforms operating in similar jurisdictions, such as E-bay operating in France and Germany should reduce the subscription fee on the jurisdiction with higher tax rate (France which has a corporate income tax rate of $34.4 \%$ ) and increase it in the jurisdiction with the lower tax rate (Germany with a corporate income tax rate of $29.8 \%$ ). This in turn will shift tax revenues from France to Germany.

\subsection{A linear model}

In the general case, when externalities are two-sided and the markets are not symmetric, the comparison of the direct and indirect effects becomes intractable. We solve the game completely in a linear model wheret $u_{A}$ and $u_{B}$ are linear in the number of users and the distributions of the parameters $\theta_{A}$ and $\theta_{B}$ are uniform over $[0,1]$. More specifically, utilities are given by

$$
u_{A}\left(x_{A}, x_{B}\right)=a x_{A}+\beta x_{B} \text { and } u_{B}\left(x_{A}, x_{B}\right)=b x_{B}+\alpha x_{A} .
$$

where the parameters $\alpha$ and $\beta$ are non-negative, reflecting the cross-externalities from $A$ to $B$ and $B$ to $A$. The parameters $a$ and $b$ reflect the externalities within jurisdictions $A$ and $B$ and can either be positive or negative depending on the applications. Recalling that the size of market $B$ is normalized to 1 and the size of market $A$ is given by $s$, the numbers of users 
$x_{A}$ and $x_{B}$ must satisfy the constraints: $0 \leq x_{A} \leq s$ and $0 \leq x_{B} \leq 1$. A market is said to be 'covered' when all users in the jurisdiction participate in the platform: hence market $A$ is covered if $x_{A}=s$ and market $B$ is covered if $x_{B}=1$.

Following the computations presented in Section 2.1, the inverse demand functions for $x_{A} \leq s$ and $x_{B} \leq 1$ are given by:

$$
\begin{aligned}
& P_{A}\left(x_{A}, x_{B}\right)=1-\sigma_{A} x_{A}+\beta x_{B} \text { with } \sigma_{A}=\frac{1}{s}-a \\
& P_{B}\left(x_{A}, x_{B}\right)=1-\sigma_{B} x_{B}+\alpha x_{A} \text { with } \sigma_{B}=1-b .
\end{aligned}
$$

The parameters $\sigma_{A}$ and $\sigma_{B}$ measure the sensitivity of the price in jurisdiction $A$ (respectively $B$ ) to the number of users in jurisdiction $A$ (respectively $B$ ). These parameters are assumed to be positive, reflecting the fact that price in a jurisdiction is decreasing in the number of users in that jurisdiction. According to the expression above, this sensitivity is decreasing both in the size of the market and in the externalities within the jurisdiction.

Effect of tax distortions on output The optimal choices of the platform depend on the tax levels only through the ratio $\rho=\frac{1-t_{B}}{1-t_{A}}$, which is increasing in $t_{A}$ and decreasing in $t_{B}$. As in the rest of the paper, we let $A$ denote the high tax jurisdiction so that $\rho \geq 1$. In line with the well-known evidence on corporate tax rates, jurisdiction $A$ is likely to be larger than jurisdiction $B$, so we also assume $s \geq 1$ in our baseline computations, even though the next proposition does not require this assumption.

Following the approach introduced in Section 3, we compute the "reaction functions " $\phi_{A}$ and $\phi_{B}$. For a fixed $x_{B}$, the profit is concave in $x_{A}$. Thus, given $\rho$ and $x_{B}$, the optimal number of users in $A, \phi_{A}\left(x_{B}\right)$, is given by

$$
\begin{aligned}
\phi_{A}\left(x_{B}\right) & =\frac{1}{2 \sigma_{A}}\left[1+(\rho \alpha+\beta) x_{B}\right] \text { if it is less than } s \\
& =s \text { otherwise. }
\end{aligned}
$$

Similarly, given $\rho$ and $x_{A}$, the optimal number of users in $B, \phi_{B}\left(x_{A}\right)$, is given by

$$
\begin{aligned}
\phi_{B}\left(x_{A}\right) & =\frac{1}{2 \sigma_{B}}\left[1+\frac{1}{\rho}(\rho \alpha+\beta) x_{A}\right] \text { if it is less than } 1, \\
& =1 \text { otherwise. }
\end{aligned}
$$

The functions $\phi_{A}$ and $\phi_{B}$ are non-decreasing, reflecting the fact that markets are complements when utility functions are linear. The numbers of users at the intersection of the two curves, abstracting from the boundary restrictions are given by $\left(X_{A}(\rho), X_{B}(\rho)\right)$ where

$$
\begin{aligned}
& X_{A}(\rho)=\frac{1}{2 \sigma_{A}}\left[\frac{1+\frac{\rho \alpha+\beta}{2 \sigma_{B}}}{1-\frac{(\rho \alpha+\beta)^{2}}{4 \rho \sigma_{A} \sigma_{B}}}\right], \\
& X_{B}(\rho)=\frac{1}{2 \sigma_{B}}\left[\frac{1+\frac{1}{\rho} \frac{\rho \alpha+\beta}{2 \sigma_{A}}}{1-\frac{(\rho \alpha+\beta)^{2}}{4 \rho \sigma_{A} \sigma_{B}}}\right] .
\end{aligned}
$$


For these values to be admissible, they must belong to the two intervals $[0, s]$ and $[0,1]$ respectively.

We assume that the parameters satisfy two conditions. (i) The platform's profit is concave and (ii) the platform's optimal choice is interior when there are no tax distortions: $\rho=1$. We next establish conditions on the parameters for which the optimal number of users are interior.

Consider first the lower bounds. The numbers $X_{A}(\rho)$ and $X_{B}(\rho)$ are negative when $1-\frac{(\rho \alpha+\beta)^{2}}{4 \rho \sigma_{A} \sigma_{B}}$ is negative. This situation only arises when the profit is not concave, as concavity of profit holds whenever $(\rho \alpha+\beta)^{2}<4 \rho \sigma_{A} \sigma_{B}$. Hence under our assumptions, the lower bounds are never binding.

Consider next the upper bounds. When both $X_{A}(\rho)$ and $X_{B}(\rho)$ are lower then upper bounds, they must be the optimal choices. When at least one number is greater than the upper bound, one of the markets must be covered.

When market $A$ is the only covered market, the optimal number of users in $B$ is given by $\phi_{B}(s)$ which is less than 1 . Hence

$$
X_{A}^{*}(\rho)=s, \text { and } X_{B}^{*}(\rho)=\frac{1}{2 \sigma_{B}}\left[1+\frac{1}{\rho}(\rho \alpha+\beta) s\right] \text { if it is less than } 1 .
$$

Similarly, when market $B$ is the only covered market, the optimal number of users in $A$ satisfy

$$
X_{A}^{*}(\rho)=\frac{1}{2 \sigma_{A}}[1+(\rho \alpha+\beta)] \text { if it is less than } s, \text { and } X_{B}^{*}(\rho)=1 .
$$

When both markets are fully covered

$$
X_{A}^{*}(\rho)=s \text { and } X_{B}^{*}(\rho)=1 .
$$

When $\rho$ is sufficiently large, the values $X_{A}(\rho)$ and $X_{B}(\rho)$ cannot be admissible. One of the two markets must be covered. We claim that market $A$ is necessarily covered. To see this, observe that if $B$ were the only fully covered market, the optimal number $x_{A}$ in $A$ given by (19), would be increasing in $\rho$ and eventually reach $s$, making market $A$ covered as well, a contradiction.

In general, identifying which market is fully covered when $X_{A}(\rho)$ and $X_{B}(\rho)$ are not admissible, requires a careful analysis and depends on the parameters. The following proposition summarizes the optimal platform's choice as a function of the externalities parameters, $\alpha$ and $\beta$, the sensitivity parameters $\sigma_{A}$ and $\sigma_{B}$, and the tax ratio $\rho$.

Proposition 4 Assume that the profit is concave and the optimal solutions are interior at $\rho=1$ : $(\alpha+\beta)^{2}<4 \sigma_{A} \sigma_{B}$ and $0<X_{A}(1)<s$ and $0<X_{B}(1)<1$. Let $\rho_{A}$ be the minimum value of $\rho, \rho>1$ for which $X_{A}(\rho) \geq s$ and $\rho_{B}$ be the minimum value of $\rho$ for which $X_{B}(\rho) \leq 1$. The optimal number of users in the two jurisdictions $\left(X_{A}^{*}(\rho), X_{B}^{*}(\rho)\right)$ is characterized as follows.

For $\rho<\min \left\{\rho_{A}, \rho_{B}\right\}$, none of the markets is fully covered and the optimal quantities are given by: $X_{A}^{*}(\rho)=X_{A}(\rho), X_{B}^{*}(\rho)=X_{B}(\rho)$.

For $\rho \geq \min \left\{\rho_{A}, \rho_{B}\right\}$, two configurations arise: 
1. $\rho_{A} \leq \rho_{B}$. Then for any $\rho \geq \rho_{A}$, market $A$ is fully covered, but not market $B$, with numbers of users given by (18): market $B$ is never covered.

2. $\rho_{A}>\rho_{B}$. Then, for values $\rho$ larger than $\rho_{B}$, market $B$ is first fully covered, but not market $A$, with numbers of users given by (19). As $\rho$ increases, the number of users in market $A$ increases until both markets are covered. As $\rho$ increases further, when $\frac{1}{2 \sigma_{B}}\left[1+\frac{1}{\rho}(\rho \alpha+\beta) s\right]<$ 1 , only market $A$ is covered and the number of users on market $B$ goes down. (Notice that this last situation only which happens when $1+\alpha s<2 \sigma_{B}$.)

Proposition 4 characterizes the optimal choices of the platform under different parameter configurations. When the difference in tax rates is sufficiently small, none of the markets are covered and the optimal number of users is computed as $X_{A}(\rho)$ and $X_{B}(\rho)$. When the difference in tax rates becomes large, one of the markets ends up being fully covered. Which market becomes fully covered first depends on the parameters.

If $\rho_{A}$ is smaller than $\rho_{B}$, market $A$ is the first market to be covered. In that case, an increase in $\rho$ unambiguously decreases $X_{B}$. The reasoning is the following: in order to shift profit from market $A$ to market $B$, the platform can no longer increase the number of users in market $A$ and will only reduce the number of users in market $B$, which is too large with respect to the efficient level in $B$, i.e. the level maximizing the sole profit in $B$, given that $x_{A}=s$.

If $\rho_{A}$ is larger than $\rho_{B}$, market $B$ is the first market to be covered. When $\rho$ increases, the platform increases the number of users in platform $A$ to shift profit towards $B$. This eventually leads to both markets being fully covered for $\rho$ sufficiently large. Then two situations may arise, as explained below. For $\rho$ large enough, the platform seeks to maximize the profit in jurisdiction $B$, given full coverage of market $A$. The platform has an incentive to reduce coverage in market $B$, if covering market $B$ given $x_{A}=s$ is not efficient, i.e. it does not maximize the profit in $B$. In that case, when $\rho$ becomes large enough, the platform reduces coverage in $B$, whereas market $A$ is fully covered. If on the other hand, given that market $A$ is fully covered, the platform would choose to cover market $B$ in order to maximize the profit in $B$, then both markets end up being fully covered in equilibrium.

An inspection of the optimal choices shows that they may be increasing or decreasing in $\rho$ depending on the parameters, and the type of equilibrium. Their behavior is easy to analyze when at least one market is covered, as discussed above, because the number of users in $A$ is increasing in $\rho$ when $B$ is covered whereas the number of users in $B$ is decreasing in $\rho$ when $A$ is covered. Hence, the differences in taxes are large enough, the marginal effect of an increase in $\rho$ is easy to sign. When instead the difference in tax levels is small, no market is covered, and the effect of an increase in $\rho$ is more complex. The functions $X_{A}(\rho)$ and $X_{B}(\rho)$ are not monotonic due to the presence of both direct and indirect effects. To illustrate this point, consider the impact of an increase in $\rho$ when $\rho$ is close to one. Easy computations show that:

$$
\begin{aligned}
& \frac{X_{A}^{\prime}(1)}{X_{A}(1)}=\frac{\alpha}{2+\alpha+\beta}+\frac{\alpha^{2}-\beta^{2}}{4 \sigma_{A} \sigma_{B}-(\alpha+\beta)^{2}}, \\
& \frac{X_{B}^{\prime}(1)}{X_{B}(1)}=-\frac{\beta}{2+\alpha+\beta}+\frac{\alpha^{2}-\beta^{2}}{4 \sigma_{A} \sigma_{B}-(\alpha+\beta)^{2}}
\end{aligned}
$$


An increase in the corporate tax rate of jurisdiction $A$ leads the platform to increase the percentage of users in that jurisdiction relative to the other jurisdiction (since $\frac{X_{A}^{\prime}(1)}{X_{A}(1)}-\frac{X_{B}^{\prime}(1)}{X_{B}(1)}>0$ ). Notice in particular that, as expected from Proposition 1 with complement markets, the number of users in jurisdiction $A$ cannot decrease while the number of users in jurisdiction $B$ increases. All other cases may arise.

When externalities are symmetric, $(\alpha=\beta)$, an increase in $\rho$ results in an increase in $X_{A}$ and a decrease in $X_{B}$ as expected from Subsection 3.2. When externalities only flow from $A$ to $B$, $\beta=0$ and $\alpha>0$, an increase in $\rho$ results in an increase in both $X_{A}$ and $X_{B}$. The result extends to the case where externalities from $A$ to $B$ are sufficiently strong relative to externalities from $B$ to $A$, in particular when $\alpha>\beta$. Similarly, when externalities only flow from market $B$ to $A$, $\alpha=0$ and $\beta>0$, an increase in $\rho$ results in a decrease in both $X_{A}$ and $X_{B}$. The result extends to the case where externalities from $B$ to $A$ are sufficiently strong relative to those from $A$ to $B$, $\alpha<\beta$, and the price sensitivities $\sigma_{A}$ and $\sigma_{B}$ are sufficiently small (but still keeping the concavity of profit, i.e. $\left.4 \sigma_{A} \sigma_{B}-(\alpha+\beta)^{2}>0\right)$. Price sensitivities are related to the externalities within jurisdictions and the jurisdiction sizes, with $\sigma_{A}=\frac{1}{s}-a$ and $\sigma_{B}=1-b$. Without externalities within jurisdictions, when $a=b=0$, and when $\alpha<\beta$, the larger the size $s$ of the high tax rate jurisdiction $A$, the more likely an increase in its corporate tax rate leads to a reduction of the number of users in both markets. This situation corresponds to a platform such as Booking connecting tourists in a large high tax rate jurisdiction $A$ with hotels in a small and low tax rate jurisdiction $B$ when externalities from $B$ to $A$ are larger than externalities from $A$ to $B$. It is explicitly solved as an example in section 2.1. It suggests that Booking reacts to an increase in the corporate tax rate of large European jurisdictions by reducing both the number of clients in large European markets and the number of hotels in small touristic destinations.

\section{Formula Apportionment}

We now turn to the second profit-sharing rule, Formula Apportionment, and characterize the optimal choice of the platform. We follow the same steps as for Separate Accounting. Assuming that the post-tax profit function is concave in $x_{A}$ and $x_{B}$, the optimal number of users is given by the solution to the two equations:

$$
\begin{aligned}
& \left(1-t_{A} \frac{x_{A}}{x_{A}+x_{B}}-t_{B} \frac{x_{B}}{x_{A}+x_{B}}\right) \frac{\partial V}{\partial x_{A}}-\frac{x_{B}\left(t_{A}-t_{B}\right)}{\left(x_{A}+x_{B}\right)^{2}} V=0, \\
& \left(1-t_{A} \frac{x_{A}}{x_{A}+x_{B}}-t_{B} \frac{x_{B}}{x_{A}+x_{B}}\right) \frac{\partial V}{\partial x_{B}}+\frac{x_{A}\left(t_{A}-t_{B}\right)}{\left(x_{A}+x_{B}\right)^{2}} V=0 .
\end{aligned}
$$

Under Formula Apportionment, a change in the number of users in any of the two jurisdictions affects the platform's post-tax profits through two channels. First, it changes the apportionment key, modifying the tax bases and the tax burdens in the two jurisdictions. Second, it changes the pre-tax profit $V$. Even in the absence of externalities between users in the two jurisdictions, the first effect creates an interdependence between the optimal choices of the platform in the two jurisdictions, and the optimal choice of the platform is affected by the corporate tax rates 
$t_{A}$ and $t_{B}$. The coexistence of these two channels greatly complicates the analysis of the optimal choice of the platform when the jurisdictions set different corporate tax rates.

As in the case of Separate Accounting, let $\psi_{A}\left(x_{B} ; t_{A}, t_{B}\right)$ and $\psi_{B}\left(x_{A} ; t_{A}, t_{B}\right)$ be the "reaction functions" defined by equations (21) and (22). The intersection of these two "reaction functions" define the platform's choices. The signs of the slopes of the marginal reactions are given by

$$
\begin{aligned}
\frac{\partial \psi_{A}}{\partial x_{B}} & =-\frac{\frac{\left(1-t_{A}\right) \frac{\partial V}{\partial x_{A}}+\left(1-t_{B}\right) \frac{\partial V}{\partial x_{B}}}{\left(x_{A}+x_{B}\right)}+\left(1-\frac{t_{A} x_{A}}{x_{A}+x_{B}}-\frac{t_{B} x_{B}}{x_{A}+x_{B}}\right) \frac{\partial^{2} V}{\partial x_{A} \partial x_{B}}}{\frac{\partial^{2} \Pi}{\partial x_{A} \partial x_{A}}}, \\
\frac{\partial \psi_{B}}{\partial x_{A}} & =-\frac{\frac{\left(1-t_{A}\right) \frac{\partial V}{\partial x_{A}}+\left(1-t_{B}\right) \frac{\partial V}{\partial x_{B}}}{\left(x_{A}+x_{B}\right)}+\left(1-\frac{t_{A} x_{A}}{x_{A}+x_{B}}-\frac{t_{B} x_{B}}{x_{A}+x_{B}}\right) \frac{\partial^{2} V}{\partial x_{A} \partial x_{B}}}{\frac{\partial^{2} \Pi}{\partial x_{B} \partial x_{B}}} .
\end{aligned}
$$

As opposed to the case of Separate Accounting, the functions $\psi_{A}\left(x_{B}\right)$ and $\psi_{B}\left(x_{A}\right)$ cannot be shown to be monotonic. The sign of the derivative $\frac{\partial \psi_{A}}{\partial x_{B}}$ depends on the signs of two terms. The first term, $\left(1-t_{A}\right) \frac{\partial V}{\partial x_{A}}+\left(1-t_{B}\right) \frac{\partial V}{\partial x_{B}}$ can either be positive or negative, depending on the tax rates $t_{A}$ and $t_{B}$ and the optimal choices of the numbers of users $x_{A}$ and $x_{B}$. This term vanishes when the tax rates are equal and there is no distortion in the optimal number of users, $\frac{\partial V}{\partial x_{A}}=\frac{\partial V}{\partial x_{B}}=0$. It is positive whenever $t_{A}>t_{B}$ and the number of users in jurisdiction $B$ is greater than the number of users in jurisdiction $A$. The sign of the second term $\left(1-\frac{t_{A} x_{A}}{x_{A}+x_{B}}-\frac{t_{B} x_{B}}{x_{A}+x_{B}}\right) \frac{\partial^{2} V}{\partial x_{A} \partial x_{B}}$ depends on the sign of the cross-derivative $\frac{\partial^{2} V}{\partial x_{A} \partial x_{B}}$. It is positive when markets are complements but negative when markets are substitutes. . We thus observe that the reaction functions are increasing when (i) markets are complements and (ii) the number of users in jurisdiction $B$ is at least as large as the number of users in jurisdiction $A$. In all other cases, it is not possible to ascertain whether the reaction functions are increasing or decreasing.

As in the case of Separate Accounting, we can decompose the effect of a change in the corporate tax rate $t_{A}$ on the number of users in jurisdiction $i, X_{i}$ into a direct and indirect effect, as $\frac{d X_{i}}{d t_{A}}$ has the same sign as

$$
\frac{\partial \psi_{i}}{\partial t_{A}}+\frac{\partial \psi_{i}}{\partial x_{j}} \frac{\partial \psi_{j}}{\partial t_{A}}
$$

We compute the direct effect using equations (21) and (22):

$$
\begin{aligned}
\frac{\partial \psi_{A}}{\partial t_{A}} & =\frac{\frac{x_{A}}{x_{A}+x_{B}} \frac{\partial V}{\partial x_{A}}+\frac{V x_{B}}{\left(x_{A}+x_{B}\right)^{2}}}{\frac{\partial^{2} \Pi}{\partial x_{A} \partial x_{A}}} \\
\frac{\partial \psi_{B}}{\partial t_{A}} & =\frac{\frac{x_{A}}{x_{A}+x_{B}} \frac{\partial V}{\partial x_{B}}-\frac{V x_{A}}{\left(x_{A}+x_{B}\right)^{2}}}{\frac{\partial^{2} \Pi}{\partial x_{B} \partial x_{B}}}
\end{aligned}
$$

The direct effect of an increase in $t_{A}$ is negative on the number of users in jurisdiction $A$, and positive on the number of users in jurisdiction $B$. 


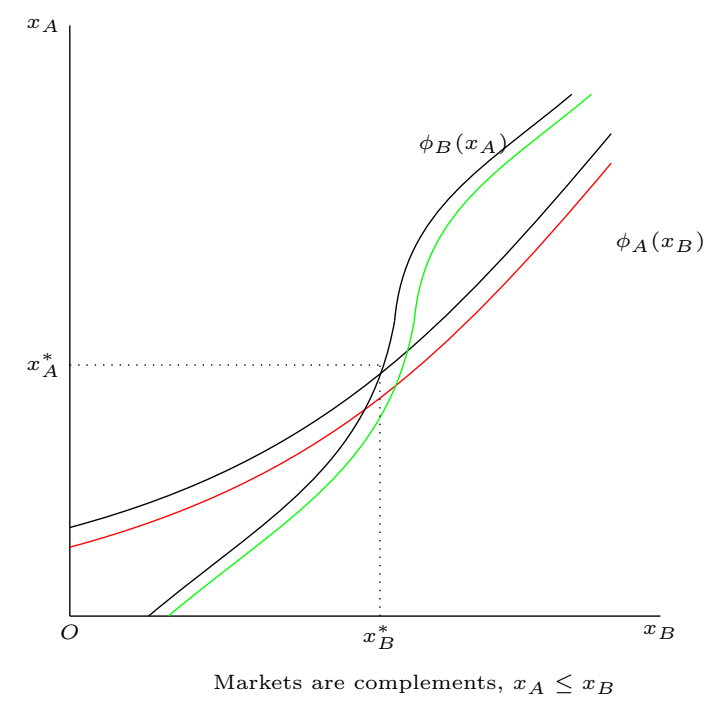

Figure 2: Effect of an increase in $t_{A}$ under FA

To see this, recall that, by equation (21),

$$
\left(1-t_{A} \frac{x_{A}}{x_{A}+x_{B}}-t_{B} \frac{x_{B}}{x_{A}+x_{B}}\right) \frac{\partial V}{\partial x_{A}}=\frac{x_{B}\left(t_{A}-t_{B}\right)}{\left(x_{A}+x_{B}\right)^{2}},
$$

so that when $t_{A} \geq t_{B}, \frac{\partial V}{\partial x_{A}}>0$. An increase in the tax rate $t_{A}$ results in a downward shift of the optimal choice on market $A$. By a similar computation, $\frac{\partial V}{\partial x_{B}}<0$, so that an increase in the tax rate $t_{A}$ results in an upward shift of the optimal choice on market $B$.

Under Formula Apportionment, an increase in the corporate tax rate in jurisdiction $A$ induces the platform to reduce its coverage in the high tax jurisdiction and increase its coverage in the low tax jurisdiction. This is easily explained: when the number of users in the low tax jurisdiction is fixed, the platform has an incentive to lower the number of users in the high tax jurisdiction in order to reduce the share of profit allocated to the high tax jurisdiction. This first order effect dominates the second-order effect of a reduction in total profit due to the distortion in output. By a similar reasoning, when the number of users in the high tax jurisdiction is fixed, the platform has an incentive to increase the number of users in the low tax jurisdiction.

We thus observe that a change in the corporate tax rate $t_{A}$ has opposite direct effects under Separate Accounting and Formula Apportionment. Under Separate Accounting, it leads to an increase in $x_{A}$ and a reduction in $x_{B}$ whereas under Formula Apportionment, it results in a decrease in $x_{A}$ and an increase in $x_{B}$.

Figure 2 illustrates the effect of an increase in the corporate tax rate on the choice of the platform when the reaction functions are increasing. As opposed to the case of Separate Accounting, an increase in the corporate tax rate in jurisdiction $A$ shifts the reaction function in jurisdiction $A$ downwards (the curve in red is below the curve in black) and the reaction function in jurisdiction $B$ upwards (the curve in green is to the right of the curve in black). The total 
effect on equilibrium depends on the balance between the direct and indirect effects which have opposite signs. In Figure 2, the direct effect dominates the indirect effect so that the platform reduces the number of users in jurisdiction $A$ and increases the number of users in jurisdiction $B$ in response to the increase in the corporate tax rate.

As in the case of Separate Accounting, an increase in the corporate tax rate $t_{A}$ always reduces the profit of the platform. By the envelope theorem, an increase in $t_{A}$ affects the profit only through the direct effect $\frac{\partial \Pi}{\partial t_{A}}=-\frac{x_{A}}{x_{A}+x_{B}} V<0$.

When the corporate tax rate $t_{A}$ increases, the variation of tax revenues in jurisdiction $A$ is given by

$$
\frac{\partial R_{A}}{\partial t_{A}}=\frac{x_{A}}{x_{A}+x_{B}} V+t_{A} \frac{x_{A}}{x_{A}+x_{B}} \frac{\partial V}{\partial t_{A}}+\frac{t_{A}}{\left(x_{A}+x_{B}\right)^{2}}\left(x_{B} \frac{\partial x_{A}}{\partial t_{A}}-x_{A} \frac{\partial x_{B}}{\partial t_{A}}\right) V
$$

The first term captures the direct effect which is always positive. The second effect captures the effect on the tax base. When $t_{A} \geq t_{B}$, an increase in $t_{A}$ increases the distortions on the platform's choice, and hence reduces the pre-tax profit $V$. Hence the second effect is negative. The third term captures the effect on the apportionment key. When the reaction functions are increasing and the direct effect dominates the indirect effect, this effect is also negative. Hence the effect of an increase in $t_{A}$ on the tax revenues of jurisdiction $A$ is ambiguous.

Consider next the effect of an increase in $t_{A}$ on the tax revenues of jurisdiction $B$ :

$$
\frac{\partial R_{B}}{\partial t_{A}}=t_{B} \frac{x_{B}}{x_{A}+x_{B}} \frac{\partial V}{\partial t_{A}}-\frac{t_{B}}{\left(x_{A}+x_{B}\right)^{2}}\left(x_{B} \frac{\partial x_{A}}{\partial t_{A}}-x_{A} \frac{\partial x_{B}}{\partial t_{A}}\right) V
$$

There is no direct effect, and the only two effects are (i) the negative effect on the tax base and (ii) the positive effect (when the reaction functions are increasing and the direct effect dominates the indirect effect) on the apportionment key.

In order to make progress, we consider two specific models: one where externalities across jurisdictions are absent and interdependence of choice only results from the effect of the apportionment key, and one where jurisdictions are symmetric and one jurisdiction contemplates an increase above an identical tax rate and a model with linear inverse demands. ${ }^{7}$

\subsection{No externalities}

Suppose that there are no externalities across jurisdictions, so that the cross-derivative $\frac{\partial^{2} V}{\partial x_{A} \partial x_{B}}$ is equal to zero. When tax rates are equal, the optimal choice of the number of users in the two jurisdictions are independent. Hence, an increase in the corporate tax rate $t_{A}$ only affects the optimal number of users through the direct effects. Furthermore, when tax rates are equal, the effect of a change in the tax rate $t_{A}$ on the tax base is negligible, so that the tax revenues in jurisdiction $B$ are increasing when $t_{A}$ increases. We summarize this discussion in the following Proposition.

\footnotetext{
${ }^{7}$ Under FA, the situation with one-sided externalities is not fundamentally different from the situation with two-sided externalities. Even if externalities do not flow from $B$ to $A$, the number of users in market $B$ affects the choice of users in market $A$ because the platform maximizes total profit, taking into account the fact that the allocation key is the ratio of the number of users.
} 
Proposition 5 (No externalities) In a situation with no externalities across jurisdictions, a small increase in the tax rate $t_{A}$ above an identical tax rate $t$ results in a decrease in the number of users in jurisdiction $A$ and an increase in the number of users in jurisdiction B. In addition, an increase in $t_{A}$ always results in an increase in the tax revenues of jurisdiction $B$.

\subsection{A symmetric model}

We next consider a model where the two jurisdictions are symmetric, and the inverse demand functions satisfy $P_{A}\left(x_{A}, x_{B}\right)=P_{B}\left(x_{B}, x_{A}\right)$ for all $x_{A}, x_{B}$. jurisdiction $A$ contemplates an increase in the corporate tax rate $t_{A}$, starting from an identical tax rate $t_{A}=t_{B}=t$. When the tax rates are equal, the sign of the slope of the reaction functions only depends on the cross-derivative $\frac{\partial^{2} \Pi}{\partial x_{A} \partial x_{B}}$. The reaction functions are increasing when markets are complements and decreasing when markets are substitutes. In addition, concavity implies that, when markets are complements, the slope of the reaction function is smaller than one, so that the direct effect always dominates the indirect effect. We conclude that an increase in $t_{A}$ always results in a decrease in $x_{A}$ and an increase in $x_{B}$. In addition, when $t_{A}=t_{B}$, the platform's choice of pre-tax profit is optimal, so that a small increase in $t_{A}$ has a negligible effect on the pre-tax profit. Hence, tax revenues in jurisdiction $B$ are always increasing when the corporate tax rate in jurisdiction $A$ increases. The following Proposition summarizes our findings.

Proposition 6 (Symmetric) In the symmetric model, a small increase in the tax rate $t_{A}$ above an identical tax rate $t$ results in a decrease in the number of users in jurisdiction $A$ and an increase in the number of users in jurisdiction B. In addition, an increase in $t_{A}$ always results in an increase in the tax revenues of jurisdiction $B$.

\section{A comparison between Separate Accounting and Formula Ap- portionment}

In this Section, we use a numerical simulation to compare equilibrium outcomes under Separate Accounting and Formula Apportionment for a peer-to-peer platform. We consider a symmetric linear model where each user's utility depends on the sum of the number of users in the two jurisdictions, with

$$
u_{A}\left(x_{A}, x_{B}\right)=u_{B}\left(x_{A}, x_{B}\right)=\gamma\left(x_{A}+x_{B}\right) .
$$

Valuations are drawn from a uniform distribution over $[0,1]$ in the two markets, and the markets have the same size, $s=1$. The inverse demand function is thus given by

$$
P_{i}\left(x_{i}, x_{j}\right)=1-(1-\gamma) x_{i}+\gamma x_{j},
$$

We compute the optimal choices of the platform under Separate Accounting and Formula Apportionment, assuming that $\gamma=0.2$ and $t_{B}=0.2$, and let the tax rate of jurisdiction $A$ increase 
from the identical tax rate $t_{A}=0.2$ to $0.4 .^{8}$ Figures 3 and 4 show how different economic variables vary with changes in $t_{A}$ under Separate Accounting (in red) and Formula Apportionment (in blue). ${ }^{9}$

Figure 3 illustrates how number of users and prices in the two counties vary when the tax rate $t_{A}$ increases. The direct effect dominates the indirect effect in the two régimes, not only at identical tax rates (as indicated by Propositions 3 and 6), but for the entire range of tax rates. Hence, an increase in $t_{A}$ results in an increase in the number of users in jurisdiction $A$ and a decrease in the number of users in jurisdiction $B$ under Separate Accounting, and a decrease in the number of users in jurisdiction $A$ and an increase in the number of users in jurisdiction $B$ under Formula Apportionment. As a consequence, prices in jurisdiction $A$ are decreasing in $t_{A}$ under Separate Accounting but increasing under Formula Apportionment. Prices in jurisdiction $B$ follow the opposite trend: they are increasing in $t_{A}$ under Separate Accounting but decreasing in $t_{A}$ under Formula Apportionment.

Figure 4 shows how profits and tax revenues are affected by an increase in the corporate tax rate $t_{A}$. The left upper panel considers pre-tax profit. Clearly, output distortions in response to the differences in corporate tax rate move the platform away from its optimal pre-tax profit. The effect becomes stronger when the difference in tax rates increases. The computations show that the effect is stronger under Formula Apportionment than under Separate Accounting. As the number of users affects the apportionment key in addition to profit, output distortions are larger under Formula Apportionment than under Separate Accounting.

When one considers post-tax profits however, the difference between the two régimes becomes less stark. As shown in the upper right panel, the post-tax profit of the platform falls at a similar rate under Separate Accounting than under Formula Apportionment. As pre-tax profits fall faster under FA than under Separate Accounting, this suggests that the total tax bill of the platform is lower under FA than under Separate Accounting.

To assess the effect of an increase in $t_{A}$ on the tax bill, we decompose the tax revenues into tax revenues received by jurisdiction $A$ (lower left panel) and jurisdiction $B$ (lower right panel). In jurisdiction $A$, we find that the direct effect of an increase in the tax level dominates the tax base effect, so that tax revenues are increasing in $t_{A}$ under both régines. In addition, it appears that the tax revenues increase faster under Separate Accounting than under Formula Apportionment, as the platform reacts more strongly to the increase of the corporate tax rate under Formula Apportionment than under Separate Accounting. Hence, the high tax jurisdiction prefers the régime of Separate Accounting to Formula Apportionment.

As indicated by Propositions 3 and 6 (for an identical tax rate), an increase in $t_{A}$ always results in an increase in the tax revenues of jurisdiction $B$. This increase is of much smaller magnitude than the increase in tax revenues of jurisdiction A. Interestingly, the increase is larger under Formula Apportionment than under Separate Accounting, so that the low tax jurisdiction prefers the régime of Formula Apportionment to Separate Accounting.

Hence, in the taxation of peer-to-peer platforms, the high tax and low tax jurisdictions

\footnotetext{
${ }^{8}$ We check that the effects that we highlight are robust to changes in the parameters. Alternative calibrations of the symmetric model give similar results.

${ }^{9}$ Robustness checks show that similar pictures are obtained for different values of $s, \gamma$ and $t_{B}$.
} 
have opposite preferences over the two régimes of profit-sharing. However, as most of the tax revenues increase accrues to the high tax jurisdiction, the sum of tax revenues is higher under Separate Accounting than under Formula Apportionment, indicating that the two jurisdictions could agree on the Separate Accounting régime with appropriate compensations to the low tax jurisdiction.

\section{Conclusion}

This paper analyzes the strategy of a monopolistic Internet platform serving users from two jurisdictions with different corporate tax rates. We show that the platform exploits positive externalities across users to shift profit, and study the effects of a change in the corporate tax rate of one of the two jurisdictions. When externalities flow symmetrically among users in both jurisdiction, the platform increases quantities in the higher-tax jurisdiction and reduces quantities in the lower-tax jurisdiction. When externalities only flow from one jurisdiction to another, the platform's response depends on the direction of externalities. If externalities originate in the higher tax jurisdiction, the platform increases quantities in the high tax jurisdiction ; if they originate in the lower-tax jurisdiction, the platform reduces quantities in the lower-tax jurisdiction. An increase in the corporate tax rate of one of the jurisdictions always increases tax revenues in the other jurisdiction. We contrast the baseline regime of separate accounting (SA) with a regime of Formula Apportionment (FA), where the tax bill is apportioned in proportion to the number of users in the two jurisdictions. Under FA, the platform always increases quantities in the lower-tax jurisdiction and decreases quantities in the higher-tax jurisdiction. We use a numerical simulation to show that the higher-tax jurisdiction prefers SA to FA whereas the lower-tax jurisdiction prefers FA to SA.

The analysis relies on the presence of externalities in demand applies to any multinational firm operating in different jurisdictions with positive network effects. While our primary application are internet platforms, other companies experiencing positive externalities across markets could also exploit externalities to shift profit to low tax jurisdictions. Finally, we ant to point out that we made several restrictive assumptions that need to be relaxed to better capture the effect of differences on corporate tax rates on multinational internet platforms. First, we need to allow for several types of users in each jurisdiction, and extend the model to an arbitrary number of jurisdictions. Second, we need to consider mobile users, and analyze the effect of tax policies on the location of users. Third, we need to allow governments to strategically choose corporate tax rates in a model of tax competition. Finally, we need to pay close attention to transfer pricing through royalties on intangible assets and rules of profit repatriation to the home jurisdiction of the platform. We hope to study all these extensions of the model in future work. 


\section{$7 \quad$ References}

Anand, B. N., and Sensing, R. (2000) "The Weighting game: Formula Apportionment as an Instrument of Public Policy," National Tax Journal 183-199.

Belleflamme, P., \& Toulemonde, E. (2016). Tax Incidence on Competing Two-Sided Platforms: Lucky Break or Double Jeopardy.

Bourreau, M., B. Caillaud and R. De Nijs (2018) "Taxation of a Digital Monopoly Platform," Journal of Public Economic Theory 20(1), 40-51.

Gordon, R., and Wilson, J. D. (1986) 'An Examination of Multijurisdictional Corporate Income Taxation under Formula Apportionment.," Econometrica 1357-1373.

Gresik, T. A. (2010). Formula Apportionment vs. Separate Accounting: A Private Information Perspective. European Economic Review, 54(1), 133-149.

Kind, H. J., Midelfart, K. H., and Schjelderup, G. (2005) "Corporate Tax Systems, Multinational Enterprises, and Economic Integration," Journal of International Economics, 65(2), 507-521.

Kind, H.J. and Koethenbuerger, M. and Schjelderup, G. (2008) "Efficiency Enhancing Taxation in Two-sided Markets," Journal of Public Economics 92(5-6), 1531-1539.

Kind, H.J. and Koethenbuerger, M. and Schjelderup, G. (2010) "On Revenue and Welfare Dominance of Ad Valorem Taxes in Two-sided Markets," Economics Letters 104(2), 86-88.

Kind, H.J. and Koethenbuerger, M. and Schjelderup, G. (2010) "Tax Responses in Platform Industries," Oxford Economic Papers 62(4), 764-783.

Kind, H.J. and Schjelderup, G. and Stähler, F. (2013) "Newspaper Differentiation and Investments in Journalism: The Role of Tax Policy," Economica 80(317), 131-148.

Kotsogiannis, C. and Serfes, K. (2010) "Public Goods and Tax Competition in a Two-Sided Market," Journal of Public Economic Theory 12(2), 281-321.

Nielsen, S. B., Raimondos-Møller, P., and Schjelderup, G. (2003) "Formula Apportionment and Transfer Pricing under Oligopolistic Competition," Journal of Public Economic Theory, 5(2), 419-437.

Nielsen, S. B., Raimondos-Møller, P., and Schjelderup, G. (2010) "Company Taxation and Tax Spillovers: Separate Accounting versus Formula Apportionment," European Economic Review, $54(1), 121-132$.

OECD (2019) Program of Work to Develop a Consensus Solution to the Tax Challenges Arising from the Digitalisation of the Economy, OECD/G20 Inclusive Framework on BEPS, available at http://www.oecd.org/tax/beps/

Weyl, E. G. (2010). A Price Theory of Multi-sided Platforms. American Economic Review, $100(4), 1642-72$. 


\section{Appendix}

Proof of Proposition 1: We have shown in the text that the signs of the effect of a change in $t_{A}$ on the number of users in jurisdiction $A$ and $B$ are respectively the same as the signs of

$$
\frac{\partial \phi_{A}}{\partial t_{A}}+\frac{\partial \phi_{A}}{\partial x_{B}} \frac{\partial \phi_{B}}{\partial t_{A}} \text { and } \frac{\partial \phi_{B}}{\partial t_{A}}+\frac{\partial \phi_{B}}{\partial x_{A}} \frac{\partial \phi_{A}}{\partial t_{A}} .
$$

and that the direct effects are $\frac{\partial \phi_{A}}{\partial t_{A}}>0$ and $\frac{\partial \phi_{B}}{\partial t_{A}}<0$.

When markets are substitutes, $\frac{\partial \phi_{A}}{\partial x_{B}}$ and $\frac{\partial \phi_{B}}{\partial x_{A}}$ are negative so that the indirect effects $\frac{\partial \phi_{B}}{\partial t_{A}} \frac{\partial \phi_{A}}{\partial x_{B}}$ and $\frac{\partial \phi_{A}}{\partial t_{A}} \frac{\partial \phi_{B}}{\partial x_{A}}$ are of the same sign as the direct effects. This proves the first part of the proposition.

When markets are complements, we prove that we cannot have a simultaneous decrease in $X_{A}$ and increase in $X_{B}$ with respect to $t_{A}$.

$X_{A}$ decreases iff $\frac{\partial \phi_{A}}{\partial t_{A}}+\frac{\partial \phi_{A}}{\partial x_{B}} \frac{\partial \phi_{B}}{\partial t_{A}}<0$, which writes, accounting for the negativity of $\frac{\partial \phi_{B}}{\partial t_{A}}$ :

$$
\frac{\partial \phi_{A}}{\partial x_{B}}>-\frac{\frac{\partial \phi_{A}}{\partial t_{A}}}{\frac{\partial \phi_{B}}{\partial t_{A}}}
$$

$X_{B}$ increases iff $\frac{\partial \phi_{B}}{\partial t_{A}}+\frac{\partial \phi_{B}}{\partial x_{A}} \frac{\partial \phi_{A}}{\partial t_{A}}>0$, which writes, accounting for the positivity of $\frac{\partial \phi_{B}}{\partial x_{A}}$ and negativity of $\frac{\partial \phi_{B}}{\partial t_{A}}$,

$$
-\frac{\frac{\partial \phi_{A}}{\partial t_{A}}}{\frac{\partial \phi_{B}}{\partial t_{A}}}>\frac{1}{\frac{\partial \phi_{B}}{\partial x_{A}}}
$$

Thus $X_{A}$ is decreasing and $X_{B}$ increasing only if

$$
\frac{\partial \phi_{A}}{\partial x_{B}} \frac{\partial \phi_{B}}{\partial x_{A}} \geq 1
$$

but we have proved in the text that the product is lower than 1 due to the concavity of profit. This contradiction completes the proof of the Proposition.

Proof of Proposition 3: Remember that the sign of $\frac{\partial X_{A}}{\partial t_{A}}$ is the same as the sign of

$$
S=\frac{\partial V_{A}}{\partial x_{A}} \frac{\partial \Pi^{2}}{\partial x_{B}^{2}}-\frac{\partial V_{A}}{\partial x_{B}}\left[\left(1-t_{A}\right) \frac{\partial^{2} V_{A}}{\partial x_{A} \partial x_{B}}+\left(1-t_{B}\right) \frac{\partial^{2} V_{B}}{\partial x_{A} \partial x_{B}}\right] .
$$

Now, suppose that $t_{A}=t_{B}=t$. By the first order condition,

$$
\frac{\partial V_{A}}{\partial x_{A}}=-\frac{\partial V_{B}}{\partial x_{A}}
$$

and by symmetry,

$$
\frac{\partial V_{B}}{\partial x_{A}}=\frac{\partial V_{A}}{\partial x_{B}}
$$


so that

$$
\frac{\partial V_{B}}{\partial x_{A}}=-\frac{\partial V_{A}}{\partial x_{A}}
$$

Note also that, as $t_{A}=t_{B}=t$,

$$
\begin{aligned}
{\left[\left(1-t_{A}\right) \frac{\partial^{2} V_{A}}{\partial x_{A} \partial x_{B}}+\left(1-t_{B}\right) \frac{\partial^{2} V_{B}}{\partial x_{A} \partial x_{B}}\right] } & =(1-t)\left(\frac{\partial^{2} V_{A}}{\partial x_{A} \partial x_{B}}+\frac{\partial^{2} V_{B}}{\partial x_{A} \partial x_{B}}\right) \\
& =\frac{\partial^{2} \Pi}{\partial x_{A} \partial x_{B}}
\end{aligned}
$$

Finally, by concavity

$$
\frac{\partial^{2} \Pi}{\partial x_{A}^{2}} \frac{\partial^{2} \Pi}{\partial x_{B}^{2}}>\left(\frac{\partial^{2} \Pi}{\partial x_{A} \partial x_{B}}\right)^{2},
$$

and by symmetry $\frac{\partial^{2} \Pi}{\partial x_{A}^{2}}=\frac{\partial^{2} \Pi}{\partial x_{B}^{2}}$ so that

$$
-\frac{\partial^{2} \Pi}{\partial x_{B}^{2}}>\left|\frac{\partial^{2} \Pi}{\partial x_{A} \partial x_{B}}\right|
$$

We find that

$$
\begin{aligned}
S & =\frac{\partial V_{A}}{\partial x_{A}} \frac{\partial \Pi^{2}}{\partial x_{B}^{2}}-\frac{\partial V_{B}}{\partial x_{A}} \frac{\partial \Pi^{2}}{\partial x_{A} \partial x_{B}} \\
& =\frac{\partial V_{A}}{\partial x_{A}}\left(\frac{\partial \Pi^{2}}{\partial x_{B}^{2}}+\frac{\partial \Pi^{2}}{\partial x_{A} \partial x_{B}}\right) \\
& >0,
\end{aligned}
$$

showing that $\frac{\partial X_{A}}{\partial t_{A}}>0$.

Now it is easy to check that $\frac{\partial X_{B}}{\partial t_{A}}=-\frac{\partial X_{A}}{\partial t_{A}}<0$. The effect of an increase in $t_{A}$ on the prices $P_{A}, P_{B}$ and the tax revenues $R_{A}$ and $R_{B}$ are immediately obtained.

Proof of Proposition 4: We have computed the reaction functions in the text. It is convenient to introduce the following functions, which give the reaction functions provided the bounds on the markets are satisfied, and make explicit the dependence with respect to $\rho$ :

$$
\begin{aligned}
\chi_{A}\left(\rho, x_{B}\right) & =\frac{1}{2 \sigma_{A}}\left[1+(\rho \alpha+\beta) x_{B}\right] \\
\chi_{B}\left(\rho, x_{A}\right) & =\frac{1}{2 \sigma_{B}}\left[1+\frac{1}{\rho}(\rho \alpha+\beta) x_{A}\right]
\end{aligned}
$$

From (24), given $\rho, \phi_{B}\left(x_{A}\right)=\min \left(\chi_{A}(\rho, x), s\right)$ and $\chi_{B}\left(x_{A}\right)=\min \left(\chi_{B}\left(\rho, x_{A}\right), 1\right)$. 
We first look for interior solutions of the optimization problem, when the market coverage constraints are not binding. The quantities are given by (16) and (17) when they are positive and smaller than $s$ and 1 respectively. The quantities are positive if $1-\frac{(\rho \alpha+\beta)^{2}}{4 \rho \sigma_{A} \sigma_{B}}>0$, which is equivalent to the concavity of profit. The inequality can be written as requiring that a quadratic function in $\rho$ is negative. This quadratic function has a positive coefficient in $\rho^{2}$ and is negative at $\rho=1$ by assumption. Thus there is value $\rho_{\min }>1$ such that the profit is concave if and only if $\rho<\rho_{\text {min }}$.

Assuming $\rho<\rho_{\text {min }}$, consider $X_{A}(\rho)$ and $X_{B}(\rho)$. The inequality $X_{A}(\rho)<s$ can be written as requiring that a quadratic function in $\rho$ with a positive coefficient in $\rho^{2}$ is negative. By a similar argument as above, there is unique value $\rho_{A}, 1<\rho_{A}<\rho_{\min }$, such that $X_{A}(\rho) \leq s$ for $\rho<\rho_{\min }$ if and only if $\rho \leq \rho_{A}$. The same argument can be used for the function $X_{B}(\rho)$ and provides the existence of a unique value $\rho_{B}, 1<\rho_{B}<1$, such that $X_{B}\left(\rho_{B}\right) \leq 1$ for $\rho<\rho_{\min }$ if and only if $\rho \leq \rho_{B}$.

This proves the first part of Proposition 4: the users' numbers $\left(X_{A}(\rho), X_{B}(\rho)\right)$ are the optimal platform choices for $\rho<\min \left(\rho_{A}, \rho_{B}\right)$.

We now consider the situation where the optimal solution is not interior.

Case 1: $\rho_{A}<\rho_{B}$. When $\rho$ increases, the market coverage constraint binds first for $A$ is but not for $B$. At $\rho=\rho_{A}, \chi_{A}\left(\rho_{A}, x_{B}\right)=s$ and $x_{B}=\chi_{B}\left(\rho_{A}, s\right)<1$. Consider $\rho>\rho_{A}$. Since $\chi_{B}(\rho, s)$ is decreasing in $\rho, x_{B}=\chi_{B}(\rho, s)<1$ holds. As for $x_{A}=\chi_{A}\left(\rho, x_{B}\right), x_{A}$ is larger than $s$ : if not, $x_{A}, x_{B}$ would be an interior solution, in contradiction with $\rho>\rho_{A}$ : Market $A$ is covered but not $B$, with quantities given by (18).

Case 2: $\rho_{A}>\rho_{B}$. When $\rho$ increases, the market coverage constraint binds first for $B$ is but not for $A$. At $\rho=\rho_{B}, \chi_{A}\left(\rho_{B}, 1\right)<s$ and $x_{B}=\chi_{B}\left(\rho_{B}, x_{A}\right)=1$.

Consider $\rho>\rho_{B}$. Since $\chi_{A}(\rho, 1)$ is increasing in $\rho$, there is a value $\widehat{\rho}$ such that $x_{A}=$ $\chi_{A}(\rho, 1)<s$ holds for $\rho \in\left[\rho_{B}, \widehat{\rho}\left[\right.\right.$ and $\chi_{A}(\widehat{\rho}, 1)=s$. The inequality $\chi_{A}(\rho, 1)<s$ for $\rho \in\left[\rho_{B}, \widehat{\rho}[\right.$ implies $\widehat{\rho}<\rho_{A}$.

Let $\rho \in\left[\rho_{B}, \widehat{\rho}\left[\right.\right.$. We surely have $\chi_{B}\left(\rho, x_{A}\right) \geq 1$ at $x_{A}=\chi_{A}(\rho, 1)$ because otherwise $\left(x_{A}, x_{B}\right)$ would be an interior solution, in contradiction with $\rho>\rho_{B}$. This also implies that $\widehat{\rho}<\rho_{A}$. Thus for $\rho \in\left[\rho_{B}, \widehat{\rho}[\right.$ market $B$ is covered but not $A$, with quantities given by (19).

Consider now $\rho \geq \widehat{\rho}=\frac{1}{\alpha}\left[2 \sigma_{A} s-\beta-1\right]$. We have $1<\widehat{\rho}<\rho_{A}$. At $\rho=\widehat{\rho}, \chi_{A}(\rho, 1)=s$ and $\chi_{B}\left(\rho, x_{A}\right) \geq 1$ so that both markets are covered. Increasing $\rho$, both markets are covered as long as $\chi_{A}(\rho, 1)>s$ and $x_{B}=\chi_{B}(\rho, s)>1$. The first inequality surely holds since $\chi_{A}$ is increasing in $\rho$. As for the second inequality, $\chi_{B}(\rho, s)$ is decreasing with $\rho$ with limit $\frac{1}{2 \sigma_{B}}\left[1+\frac{1}{\rho}(\rho \alpha+\beta) s\right]$. Thus $x_{B}=\chi_{B}(\rho, s)>1$ always holds if the limit is at least one; otherwise, $2 \sigma_{B}<1+\alpha s$. it becomes optimal to decrease the number of users at the value $\rho$ for which $\chi_{B}(\rho, s)=1$ with an optimal number of users is given by $\chi_{B}(\rho, s)$.

We have worked by increasing $\rho$, analyzing the solutions to the first order conditions. Since the profit is not always concave, it remains to check that there are not multiple solutions. We know that an interior solution is the unique optimum. We thus need to check that we cannot have two solutions, each with at least one covered market. This is proven as follows. Let there be a solution with $B$ being covered. Assume $A$ is covered as well: covering a market is the best 
response to the other being covered, hence it is the unique solution with one covered market at least. Assume now that $A$ is not covered. An alternative solution could be that $A$ is covered but not $B$, which implies $\chi_{A}\left(\rho, x_{B}\right) \geq s$ with $x_{B}=\chi_{A}(\rho, s)<1$. As $\chi_{A}\left(\rho, x_{B}\right)$ is increasing in $x_{B}$, we must have $\chi_{A}(\rho, 1)>s$ : it is optimal to cover $A$ if $B$ is covered, in contradiction with the initial assumption.

Proof of Proposition 6: When the jurisdictions are symmetric and $t_{A}=t_{B}$, then $x_{A}=x_{B}$ and $\frac{\partial V}{\partial x_{A}}=\frac{\partial V}{\partial x_{B}}=0$. This implies that

$$
\begin{aligned}
\frac{\partial \psi_{A}}{\partial x_{B}} & =-\frac{\frac{\partial^{2} \Pi}{\partial x_{A} \partial x_{B}}}{\frac{\partial^{2} \Pi}{\partial x_{A}^{2}}} \\
\frac{\partial \psi_{B}}{\partial x_{A}} & =-\frac{\frac{\partial^{2} \Pi}{\partial x_{A} \partial x_{B}}}{\frac{\partial^{2} \Pi}{\partial x_{B}^{2}}} .
\end{aligned}
$$

Hence

$$
\frac{\partial X_{A}}{\partial t_{A}}=\frac{\frac{V x_{B}}{\left(x_{A}+x_{B}\right)^{2}}}{\frac{\partial^{2} \Pi}{\partial x_{A}^{2}}}+\frac{\frac{V x_{A}}{\left(x_{A}+x_{B}\right)^{2}}}{\frac{\partial^{2} \Pi}{\partial x_{B}^{2}}} \frac{\frac{\partial^{2} \Pi}{\partial x_{A} \partial x_{B}}}{\frac{\partial^{2} \Pi}{\partial x_{A}^{2}}} .
$$

Now by symmetry $\frac{\partial^{2} \Pi}{\partial x_{A}^{2}}=\frac{\partial^{2} \Pi}{\partial x_{B}^{2}}$ and, by concavity,

$$
\left(\frac{\partial^{2} \Pi}{\partial x_{A}^{2}}\right)^{2}-\left(\frac{\partial^{2} \Pi}{\partial x_{A} \partial x_{B}}\right)^{2}>0 .
$$

Hence

$$
\left|\frac{\frac{\partial^{2} \Pi}{\partial x_{A} \partial x_{B}}}{\frac{\partial^{2} \Pi}{\partial x_{A}^{2}}}\right|<1
$$

which guarantees that

$$
\begin{aligned}
\frac{\partial X_{A}}{\partial t_{A}} & <\frac{\frac{V x_{B}}{\left(x_{A}+x_{B}\right)^{2}}}{\frac{\partial^{2} \Pi}{\partial x_{A}^{2}}}-\frac{V x_{B}}{\frac{\left(x_{A}+x_{B}\right)^{2}}{\partial x_{A}^{2}}} \\
& <0
\end{aligned}
$$

so that $X_{A}$ is decreasing in $t_{A}$. A similar computation shows that $x_{B}$ is decreasing in $t_{A}$. Next observe that $\frac{\partial V}{\partial t_{A}}=0$ at $t_{A}=t_{B}=t$, so that an increase in the corporate tax rate always increases the tax revenues of jurisdiction $B$, concluding the proof. 


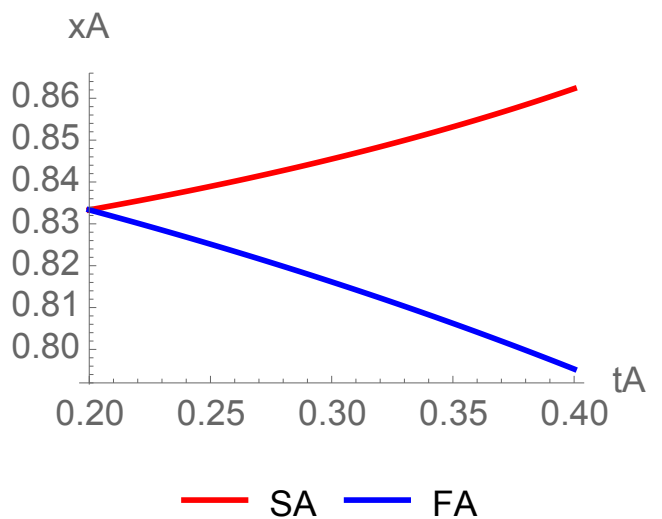

output in country $A$

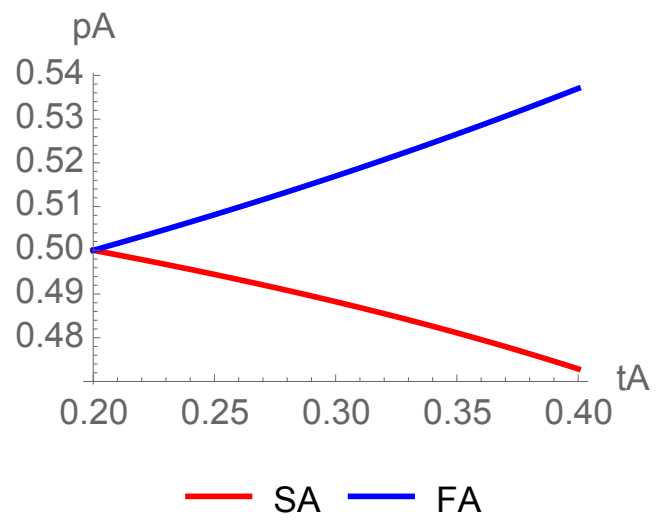

price in country $A$
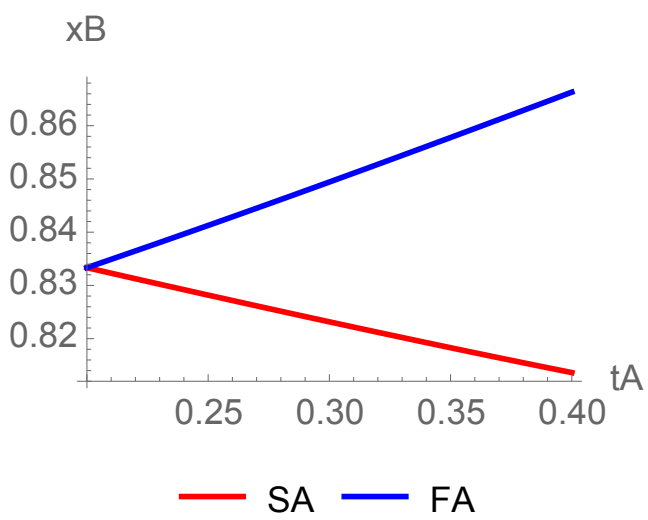

output in country $B$

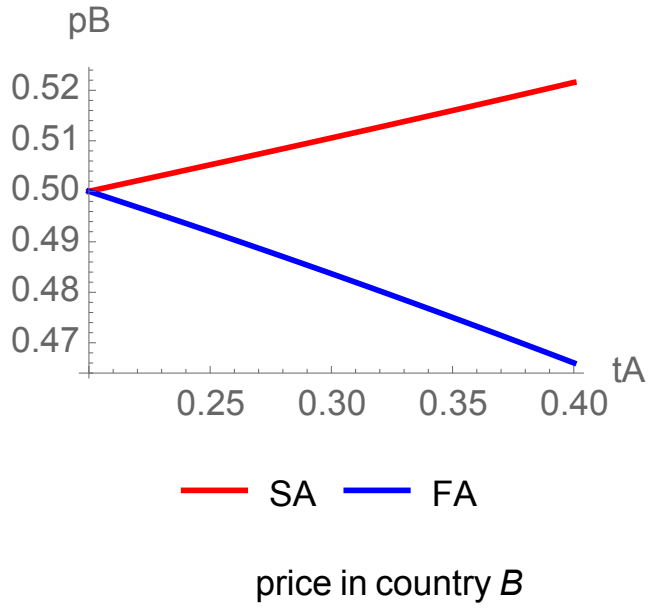

Figure 3: Outputs and prices 


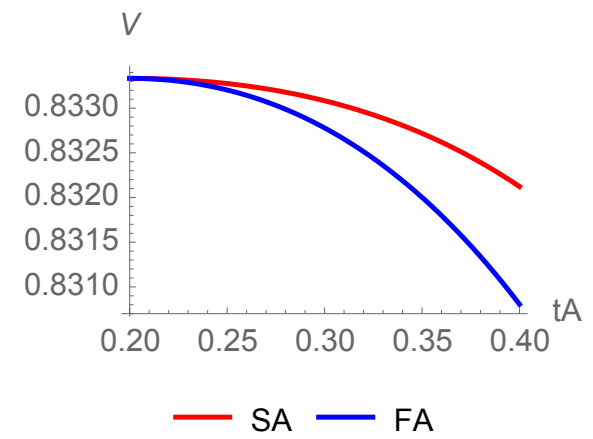

pre - tax profit

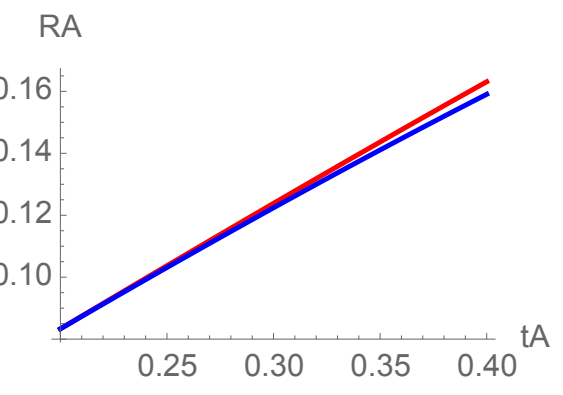

$\longrightarrow$ SA - FA

tax revenues country $A$

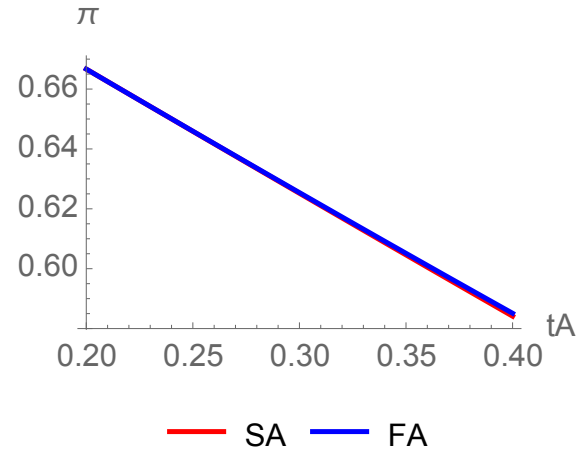

post - tax profit

RB

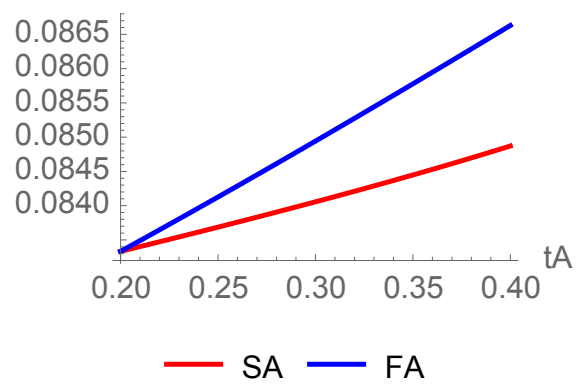

tax revenues country $B$

Figure 4: Profits and revenues 